\title{
Advocating for Open: Putting Ethics Into Practice
}

\author{
Brianna Marshall, UC Riverside | @notsosternlib \\ Vicky Steeves, New York University | @vickysteeves \\ Micah Vandegrift, NC State University | @micahvandegrift
}

Session hashtag: \#openACRL2019 - tweet or toot us! 


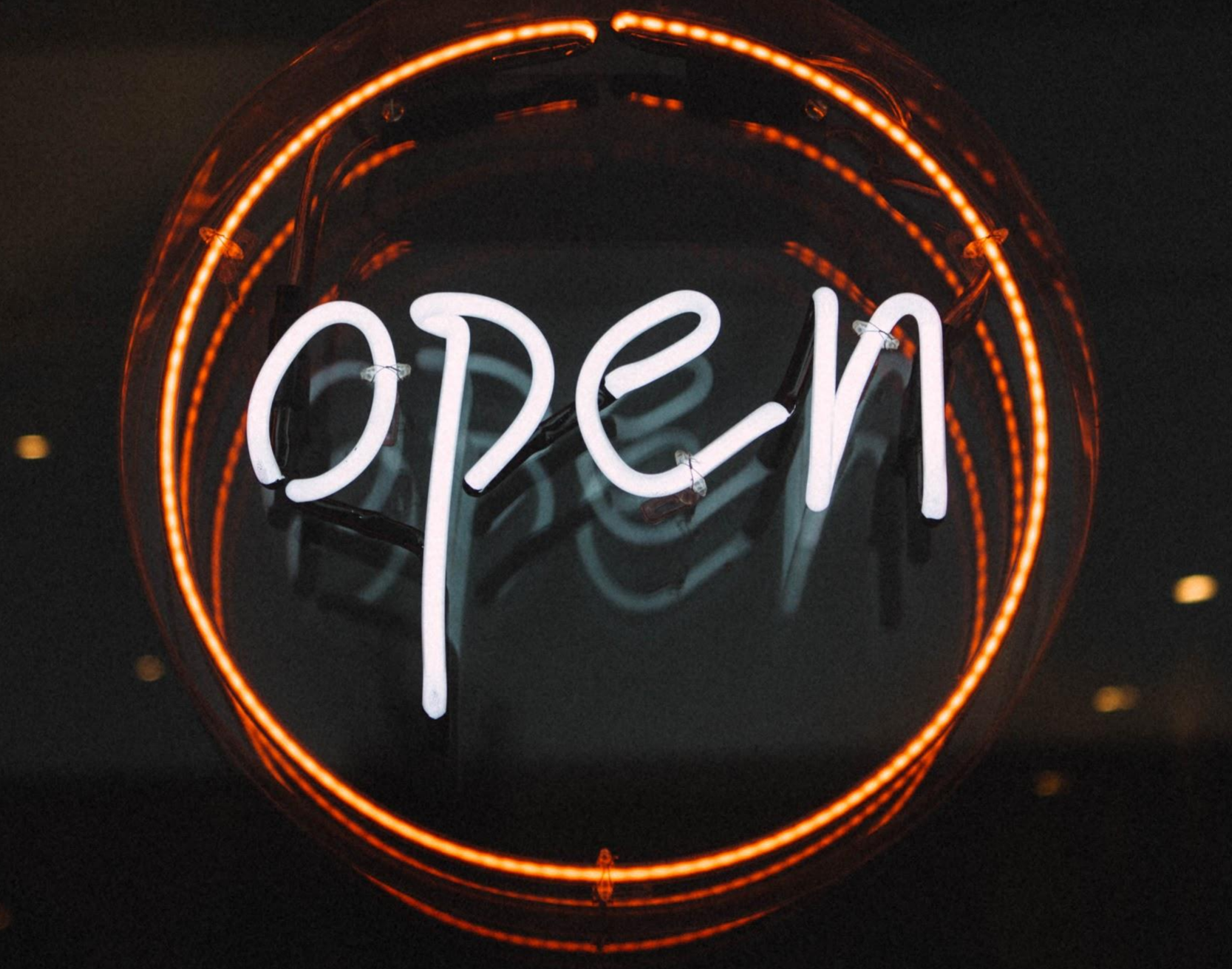

Group notes: http://tinyurl.com/y5lxmu3x 


\section{Ethics in daily practice}

A little about my journey first?

I did computer science in my undergrad at a small all-women's college

My compsci degree required two philosophy classes and one ethics class

When I graduated, my professors paid their own money to induct me and my 5 fellow graduates with...

\section{The Pledge of the Computing Professional!}

I've continued this trend by registering NYU as a member in the org:)

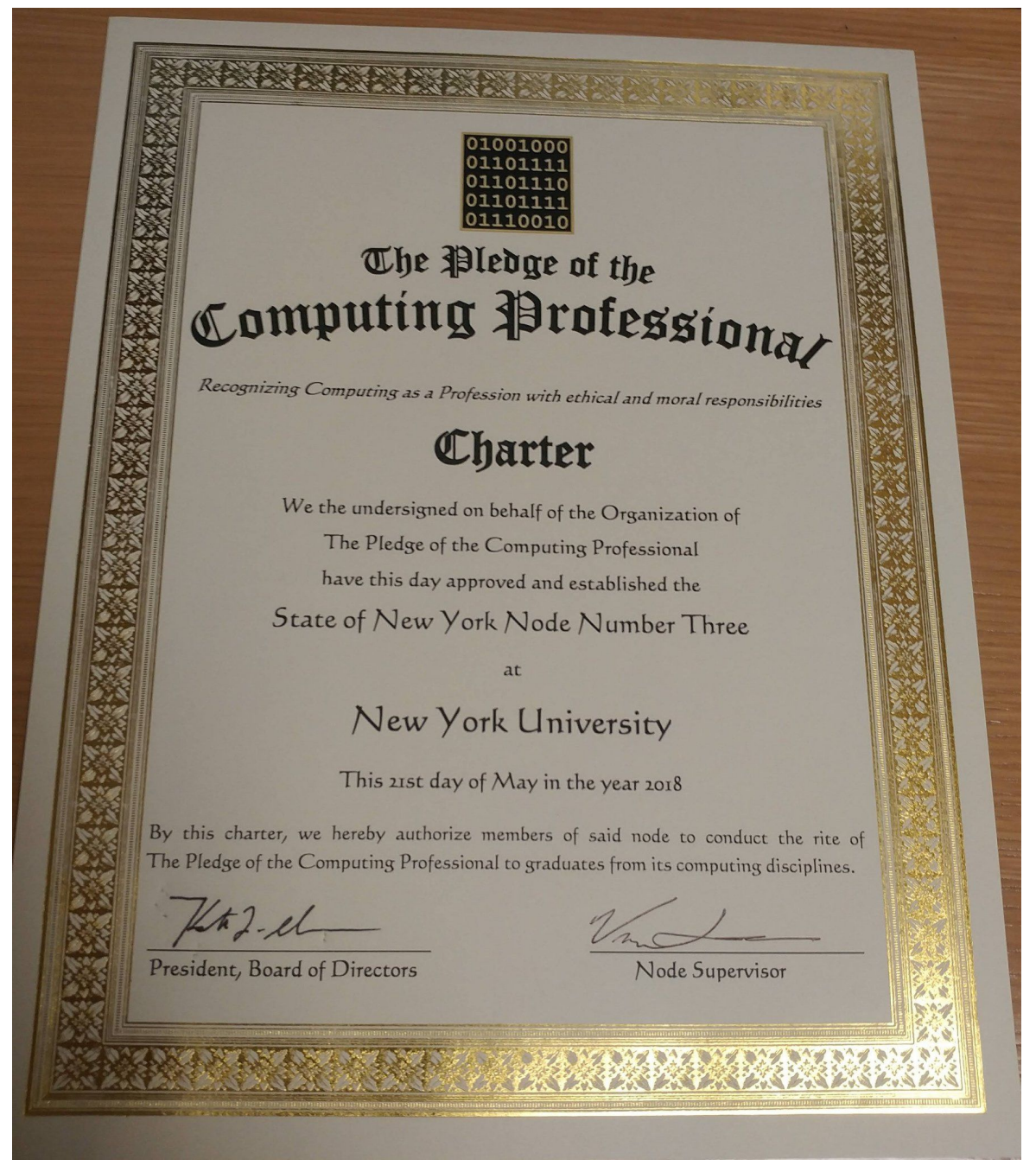


Advocacy in service design

\section{Ethical considerations:}

- Affordability

- Transparency

- Continuity

Daily practice:

- OER everything

- FLOSS tools only

- Open infrastructure building toujours

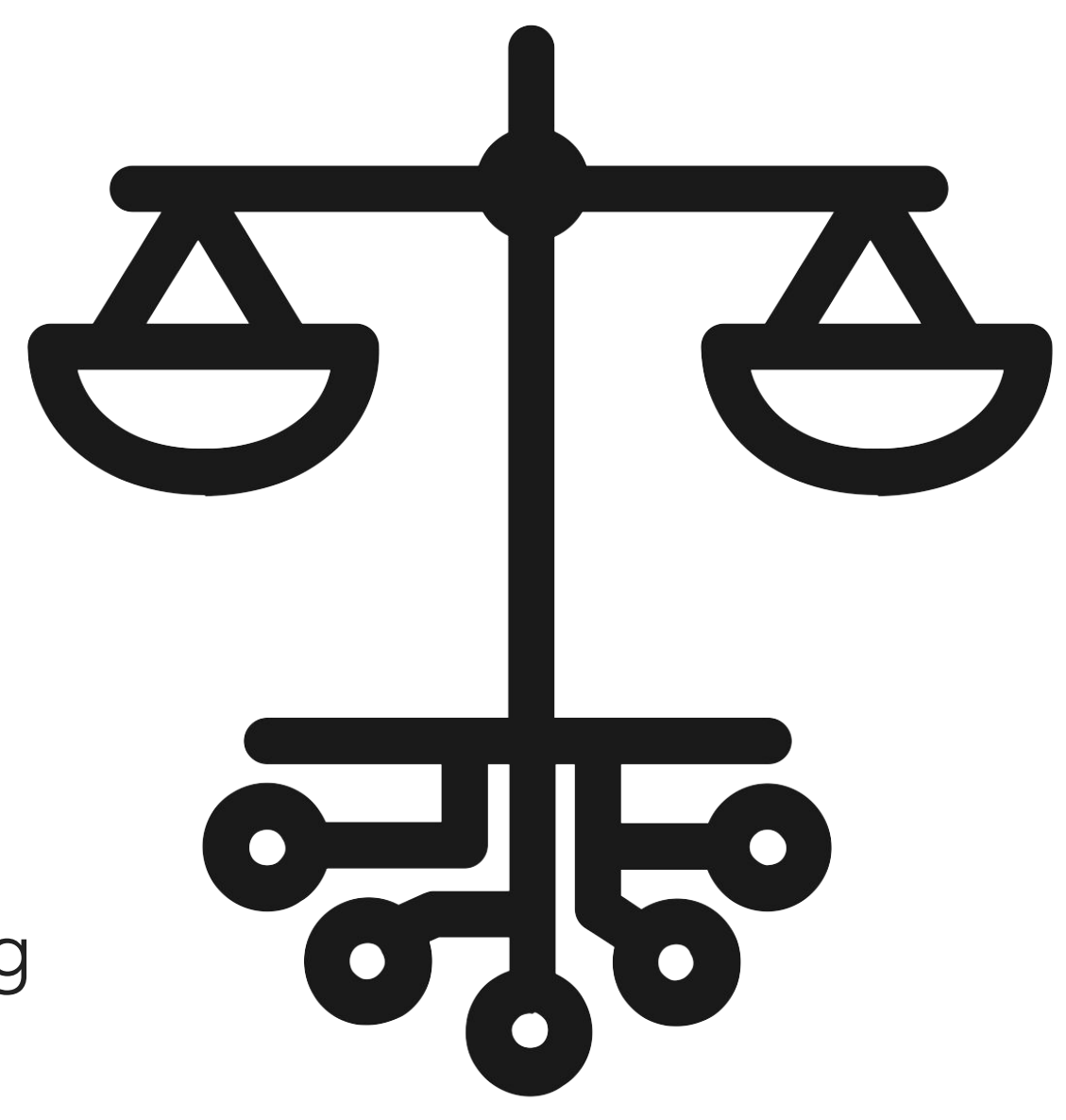


Daily practice: teaching with FLOSS tools

- Supporting community and consortial development is important!
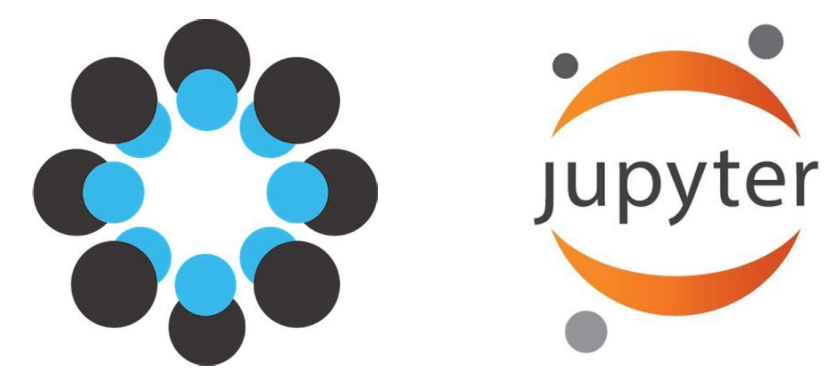

- Line between research + dev is increasingly blurred

- Dewey: "All conduct is social"

- What I teach learners, they should be able to keep with them without paying massive fees (close tie to lock-in also)

- Learning curve is potentially steeper, but long-term...
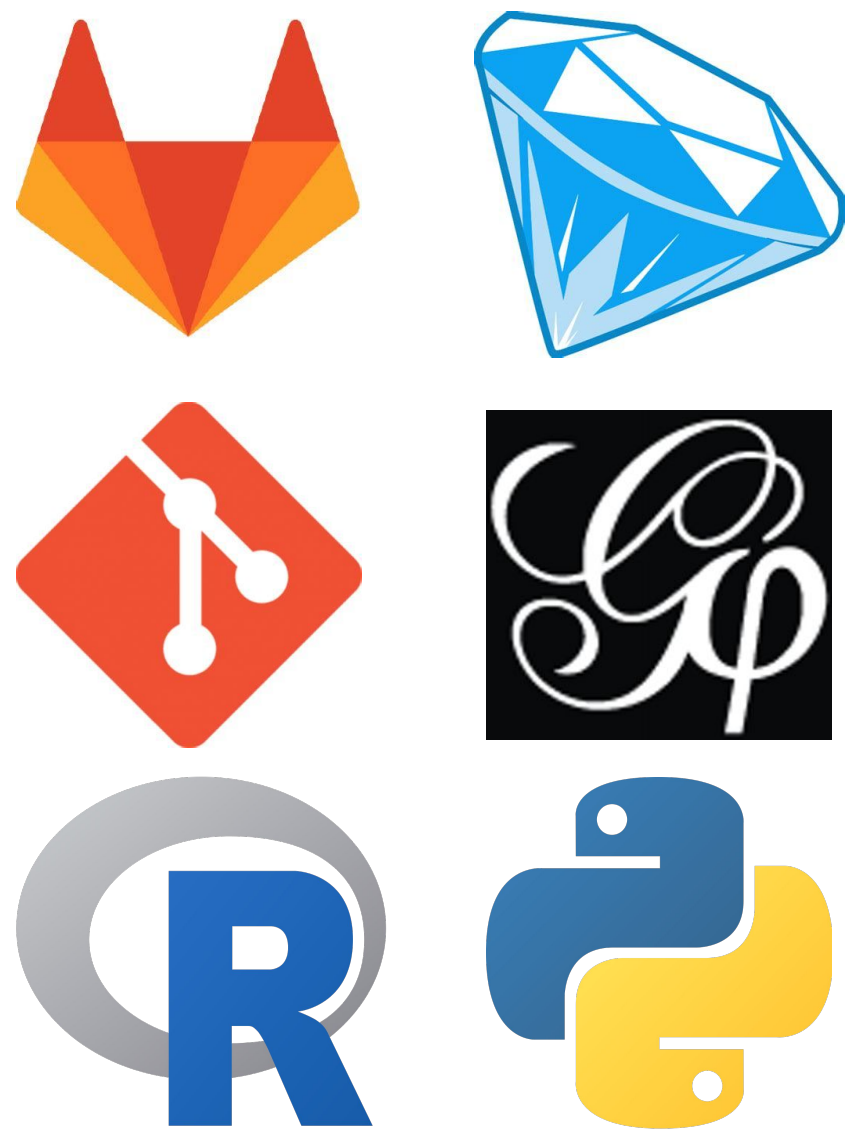


\section{Daily practice: open educational resources}

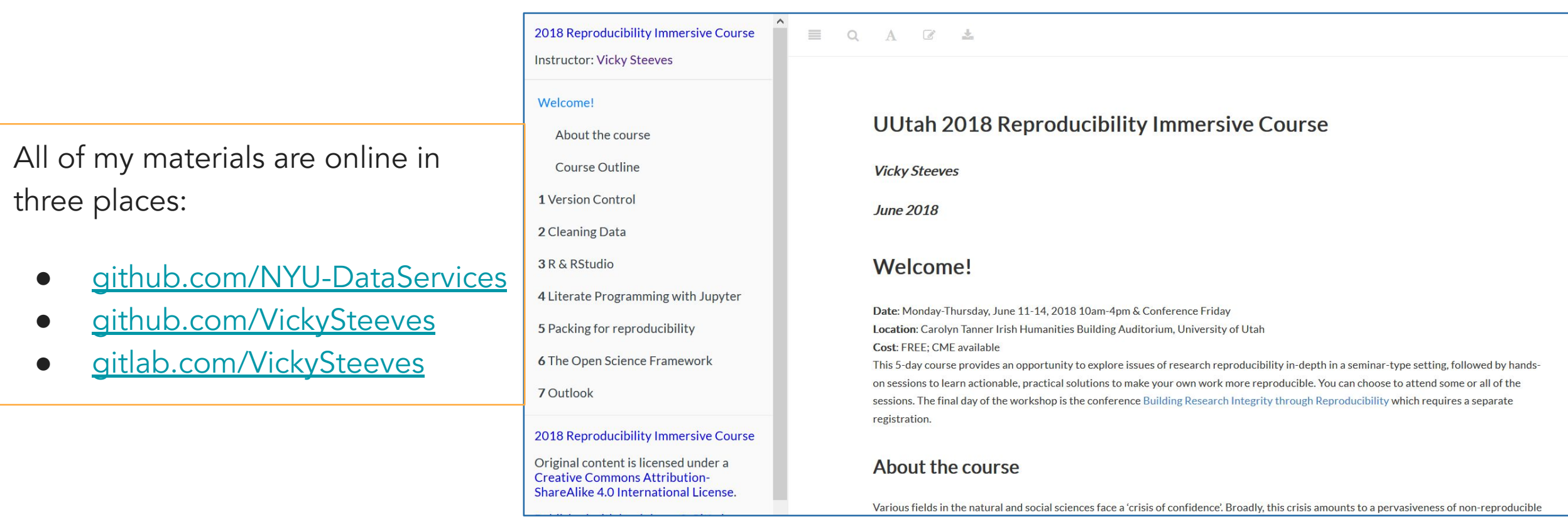

Why do this?

- Give back to community -- materials are freely licensed!

- I want librarians with 0 money to be able to teach $\mathrm{RDM}$ /reproducibility best practices

- Solicit feedback from community -- directly + openly - Learners have access to materials where they aren't tracked 


\section{Daily practice: infrastructure building}

Questions I use to guide myself:

- How is my work contributing to or disrupting the corporate capture of scholarship?

- ReproZip, open source reproducibility tool!

- What options exist for researchers in that are free/libre open source? What is the gap?

- Taguette, open source qualitative analysis tool!
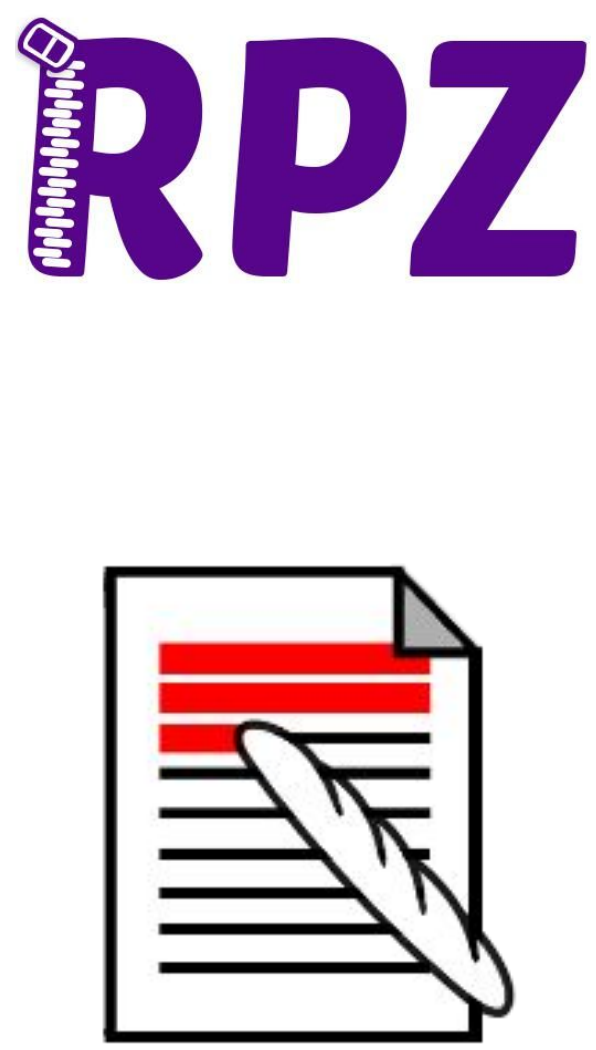
Advocacy for \& with patrons

\section{Ethical considerations:}

- Empowerment

- Care [see: ethics of care]

- Community goods

Daily practice:

- Navigating open* landscape, terms, etc.

- Enabling patrons to make

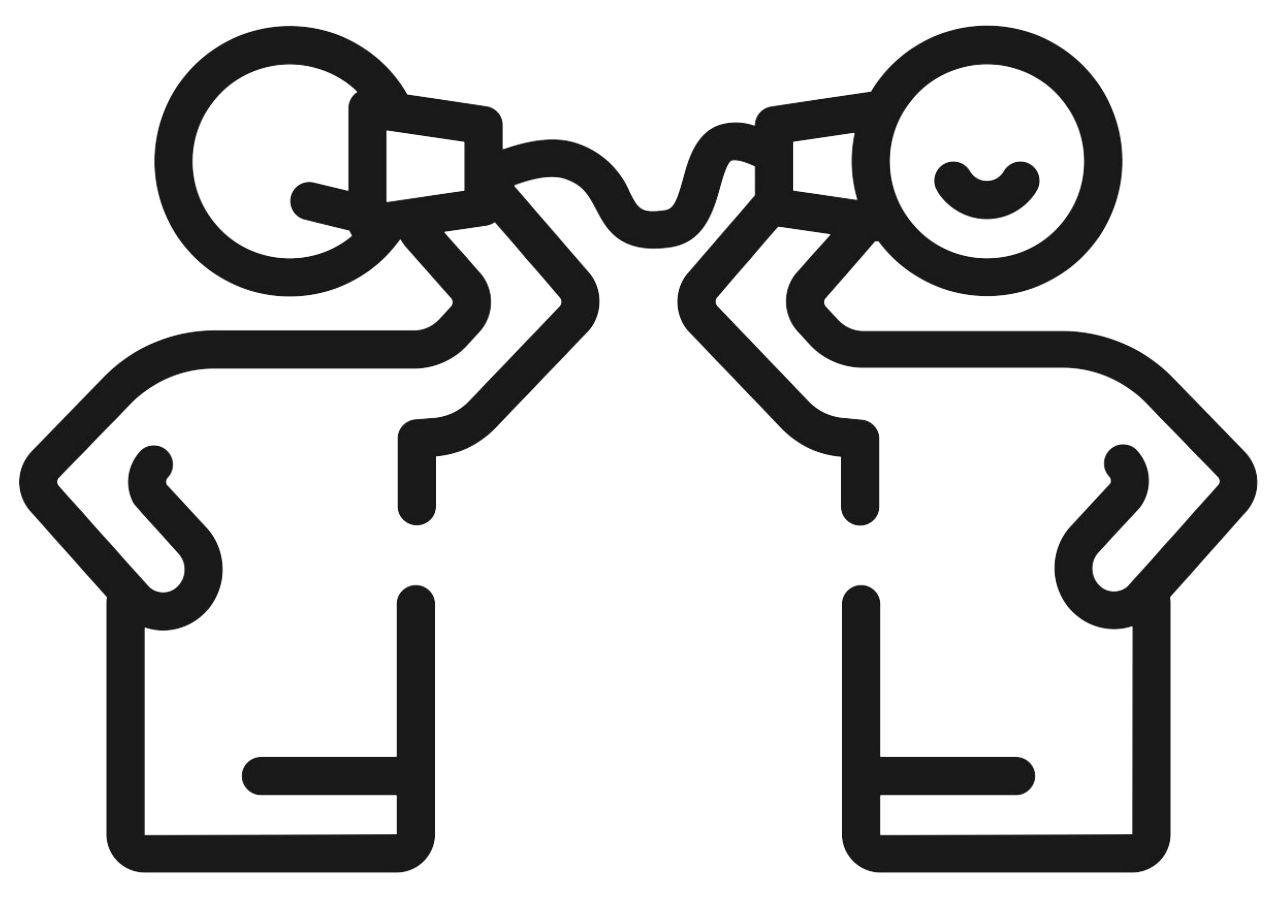
choices about their work

- When open isn't the best option... 


\section{Daily practice: navigating opening their work}

A part of my job is about empowering my patrons to investigate choices!

- Data + code publishing in particular (to the right is an actual email from a grad student)

- Providing options is EVERYTHING

- Screaming 'negotiate' \& empowering that behaviour

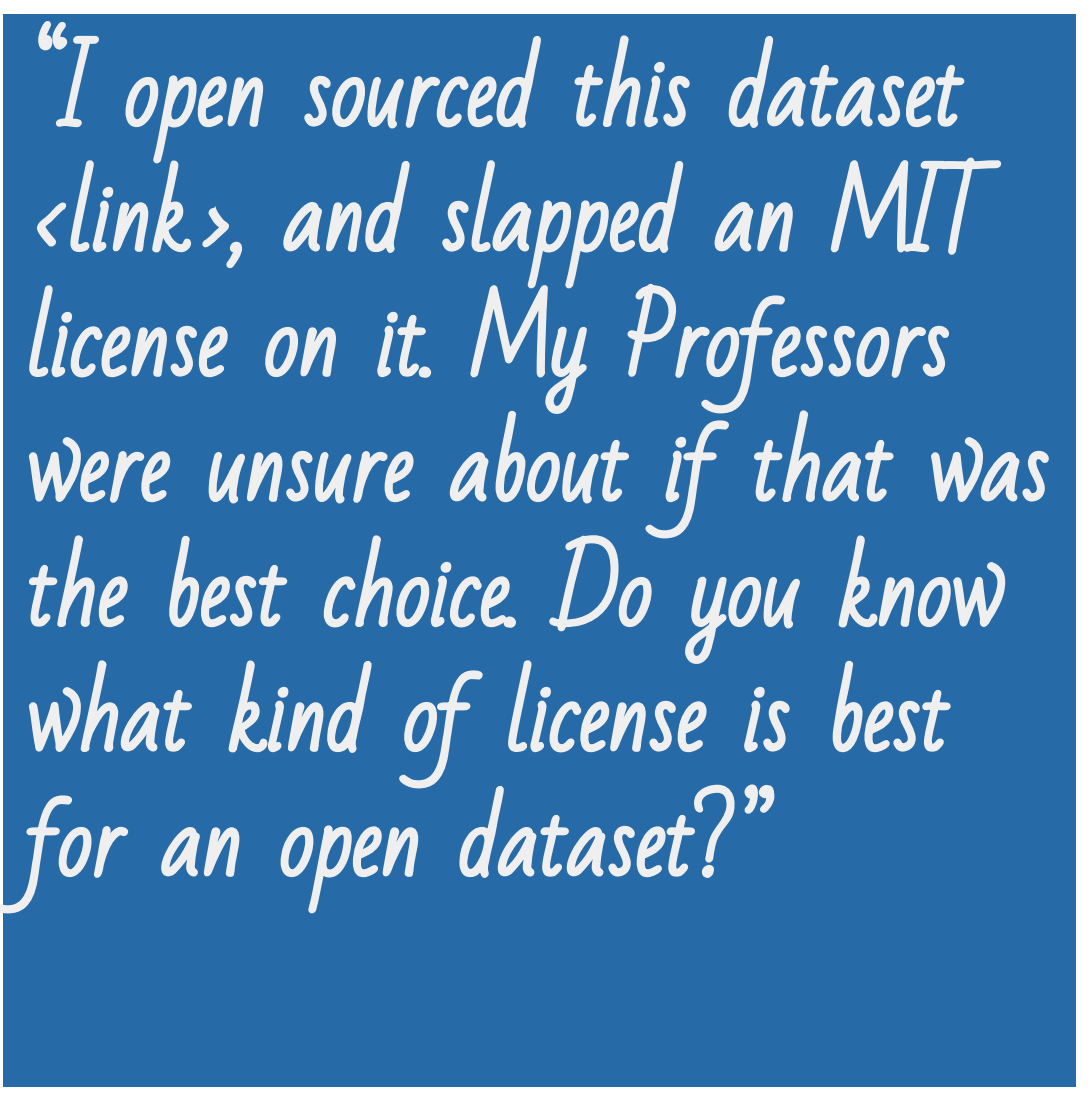

"I open sourced this dataset slinks, and slapped an MIT license on it. My Professors were unsure about if that was the best choice. Do you know what kind of license is best for an open dataset?" 


\section{Daily practice: sounding board for ethical questions}

- Especially with my dual appointment with the CDS -use of public data and ethics around that (e.g. twitter data)

- Discuss ethical implications of publishing/sharing

○ e.g. navigating $\mathrm{Q}$ : " is it ethical to publish closed" or "is it ethical to not share code/data that underlies claims in a paper"

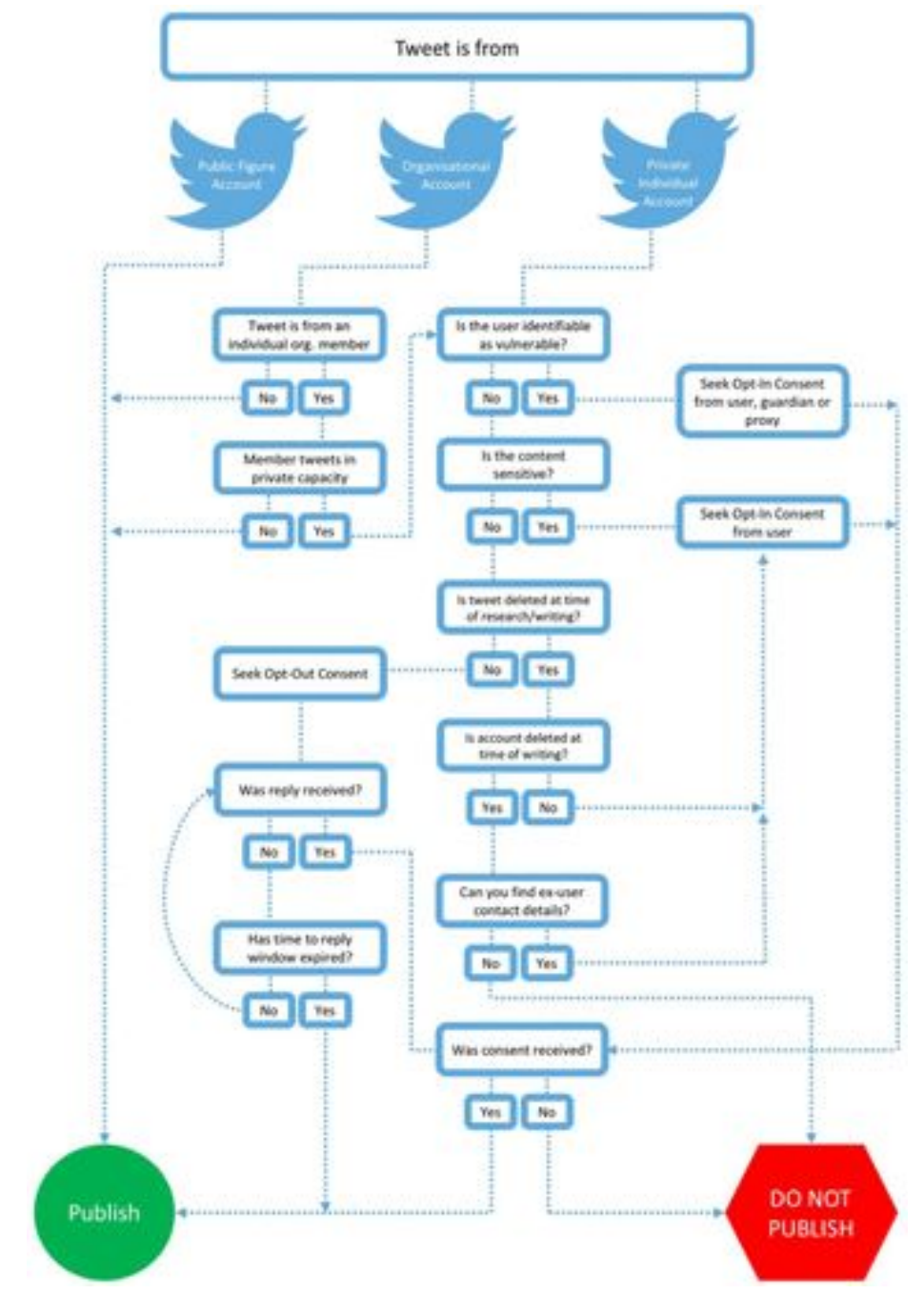

Williams, Matthew L, Pete Burnap, and Luke Sloan. "Towards an Ethical Framework for Publishing Twitter Data in Social Research: Taking into Account Users' Views, Online Context and Algorithmic Estimation." Sociology 51, no. 6 (December 2017): 1149-68. https://doi.org/10.1177/0038038517708140. 


\section{Lateral advocacy -- with colleagues!}

\section{Ethical considerations:}

- Public goods

- Skepticism

- Consistency

Daily practice:

- Walkin' the walk, even when it's scary

- Space for students to interrogate openness

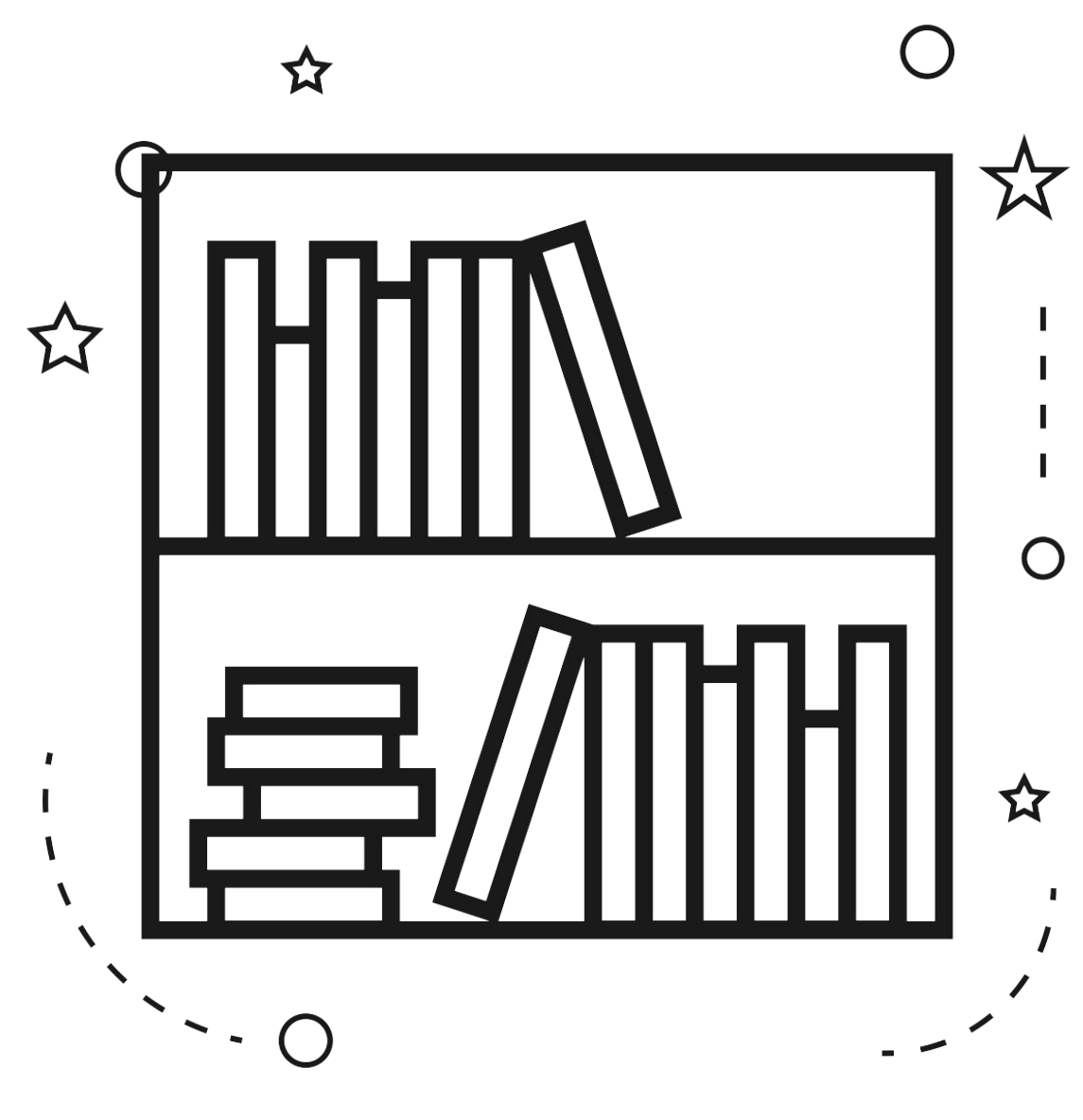

- Community projects! 
Daily practice: within NYU's community

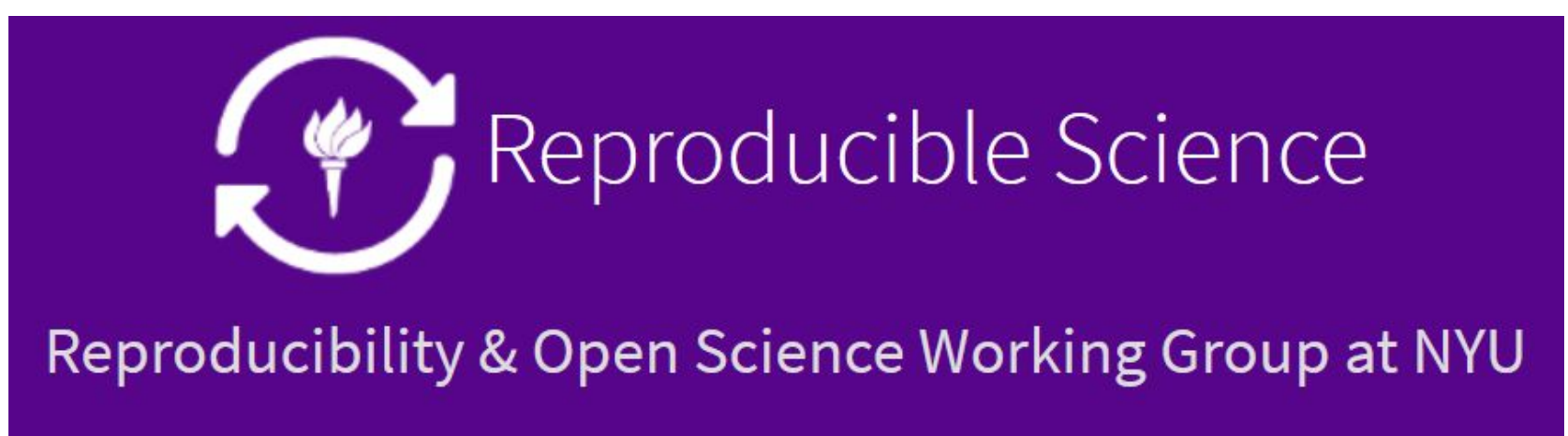

Some university-wide initiatives:

- Bringing openness into conversations in governance bodies (C-FSC, FTEE committee)

- Most recently, looked at MOU for adjuncts!

- In past: drafting OA policy

- Reproducibility and Open Science Working Group @ Center for Data Science -- so much outreach! 


\section{Daily practice: with LIS students!}

\section{Schield}

- What does it mean to say that data is socially constructed? how can we address this idea through data, statistical, and information literacy instruction?

- In considering critical pedagogy, what are the ways in which data can be seen to reinforce hegemonic power structures and the status quo?

5. In Invisible Labor and Digital Utopias, Audrey Waters reflects on her relationship with the word 'open' and how it has evolved over time, specifically with CC licensing and her websites. How has your relationship with 'open' evolved after reading this week's five assigned articles?

- In addition, what do you think about her comparison of 19th century capitalist exploitation of labor and the invisibility of digital labor in our current time?

$\circ$ What would Marx think?

- Teaching 'Data Librarianship' - embedded ethics throughout - Up front discussions with students as to why I don't use LMS; give them outs if they are uncomfortable with that

- Encourage openness but I don't require it 


\section{Daily practice: in LIS broadly}

I want us to walk the walk!

- LIS Scholarship Archive -free/libre open source FOR open scholarship!

- Emailing/tweeting/tooting at people (very nicely! With nuance!) asking they make their scholarship open

- Participation in advocacy

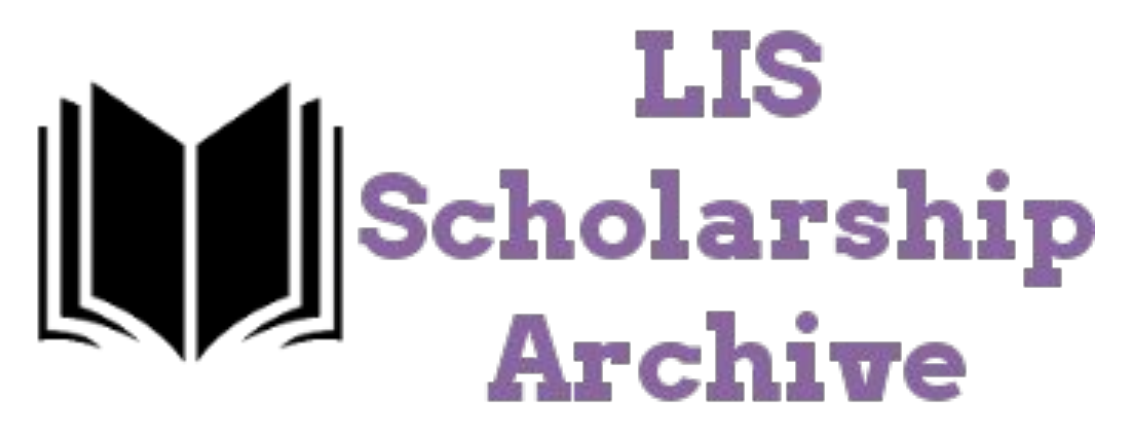
organizations (e.g. Software Preservation Network)
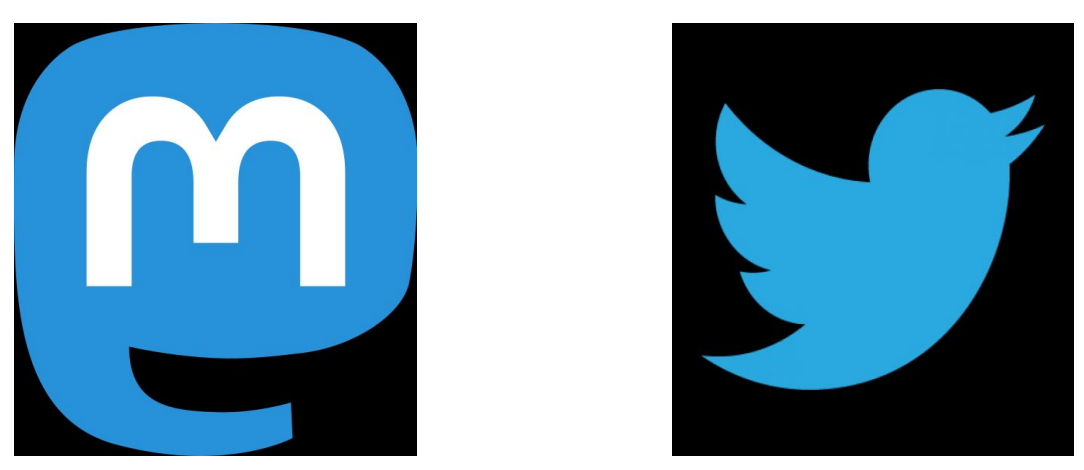
Other things I may/may not have time to talk about:

- MANAGING UP is so important

- Communicating ROI for open, community infrastructure to higher administration can be challenging, especially across university bodies

- Autonomy in service/research design \& who gets it

- Ethical implications for working at a historically and/or currently super unethical institution

- Feminization of labour and how that intersects with my work in 'open', especially the ethics of care \& feminism 


\section{Takeaways for your own daily practice}

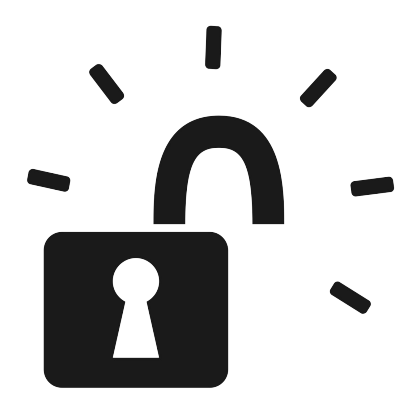

- You can contribute to the open movement in so many ways, at such varying levels of scale

- Choose how you'll embed open values in your practice

- Open* is about choice, and that manifests in a lot of ways (e.g. vendor lock-in, lack of access to research software)

- Always, always negotiate your contracts (unless they are randomly amazing!) \& empower others to do so

- Pay attention to what makes you both comfortable and uncomfortable in the open space, and interrogate that 
An open-related challenge is getting the library and colleagues to think differently about our ideas for advocating or "promoting" open access... We should move away from this "build it and they will come" mentality and see creators and users as more than just a "customer" to buy into open... open in action shows its possibilities, impacts and values, which ideally means a sense of community. Open is really more of a lifestyle or culture of practice -- people should feel a part of that rather than being told how to practice being an academic. I believe open advocacy supports leadership practices in LIS as well because you are managing projects, interacting with a variety of stakeholders and demonstrate the libraries' labor and value every time you represent open. Personally, I think there is way more to be said about open praxis being open advocacy than any workshop.

Camille Thomas is the Scholarly Publishing Librarian at Texas Tech University in Lubbock, Texas. She currently supports students, faculty and staff with copyright information, publishing best practices and adoption of open resources at Texas Tech.

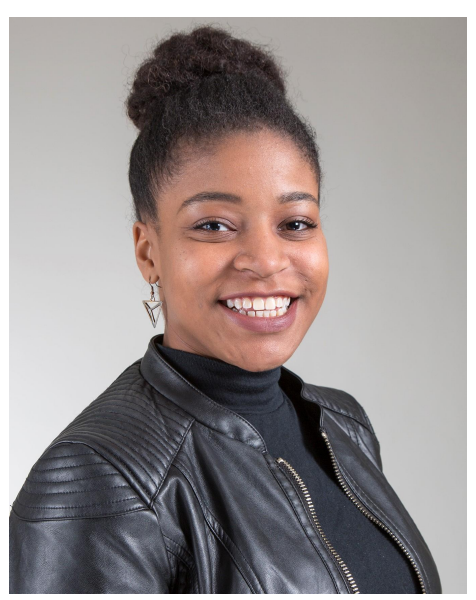




\section{Open Advocacy \\ Practices:}

A New Manager's

Perspective

Group notes: http://tinyurl.com/y5|xmu3x 
Reflecting on what I've

learned incorporating open

values \& practices into a new department.

- Encouragement for managers who aren't sure where to start

- Build community and conversation around how we develop (open-focused) research support structures in libraries

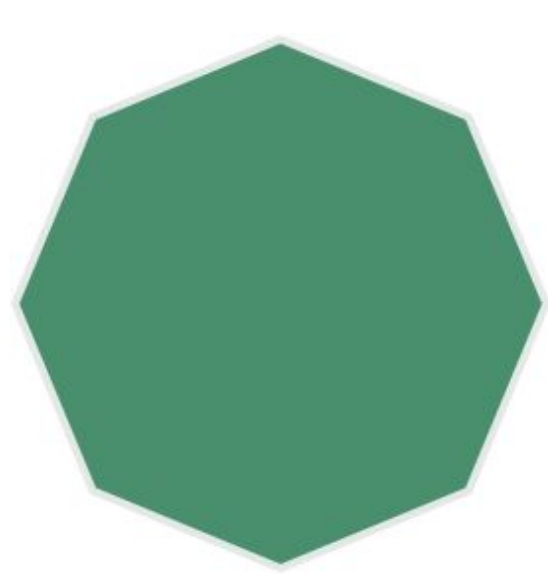




\section{"In putting their knowledge into practice, RSD staff will prioritize facilitating open research and, if possible, providing alternative solutions to closed platforms and processes."}



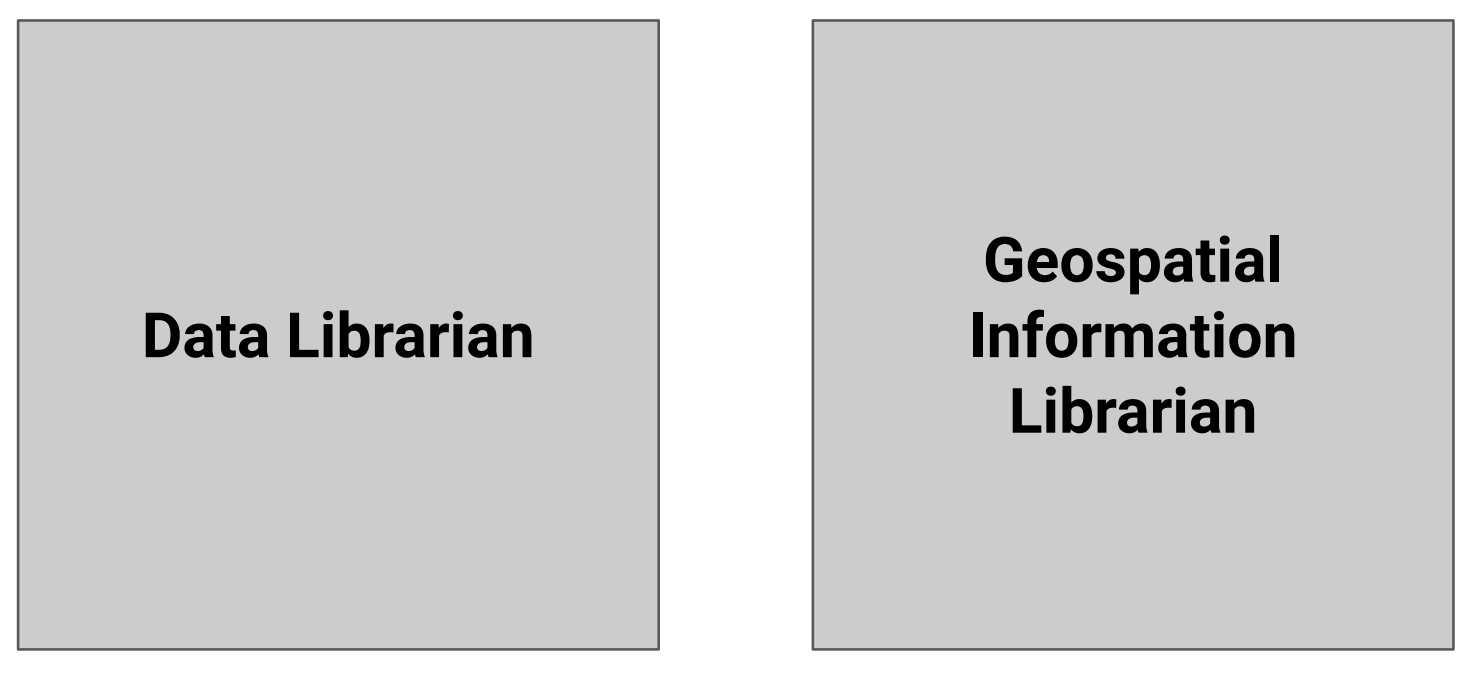

Maker Services

Librarian

\section{Research Services Roles at UCR Library}
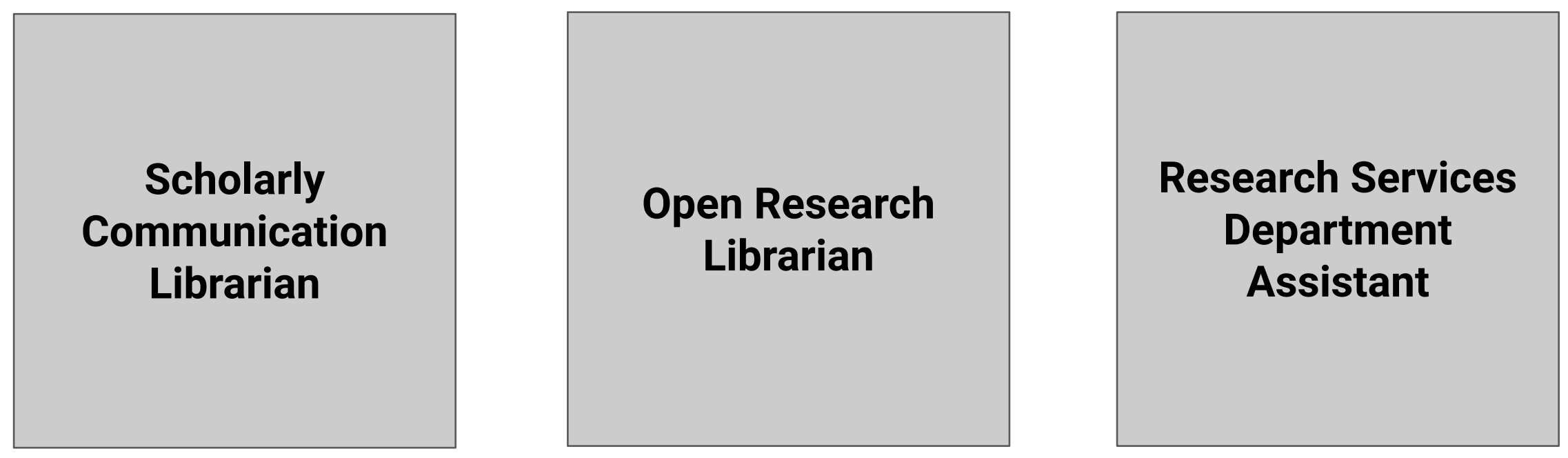


\section{Open Research Librarian}

Information gathering, confidence building, and charting a new path

- Consultations about open research and reproducibility

- Connecting with open research support partners on campus

- Teaching open tools and advocating for open licensing

- Writing a strategic plan, including an environmental scan listing internal (campuswide) and external (professionwide) support, SWOT analysis, and service plan and recommendations

- Pitching a pilot project focused on making lab visits and surveying research workflows and documentation practices 


\section{Open advocacy is for everyone!}
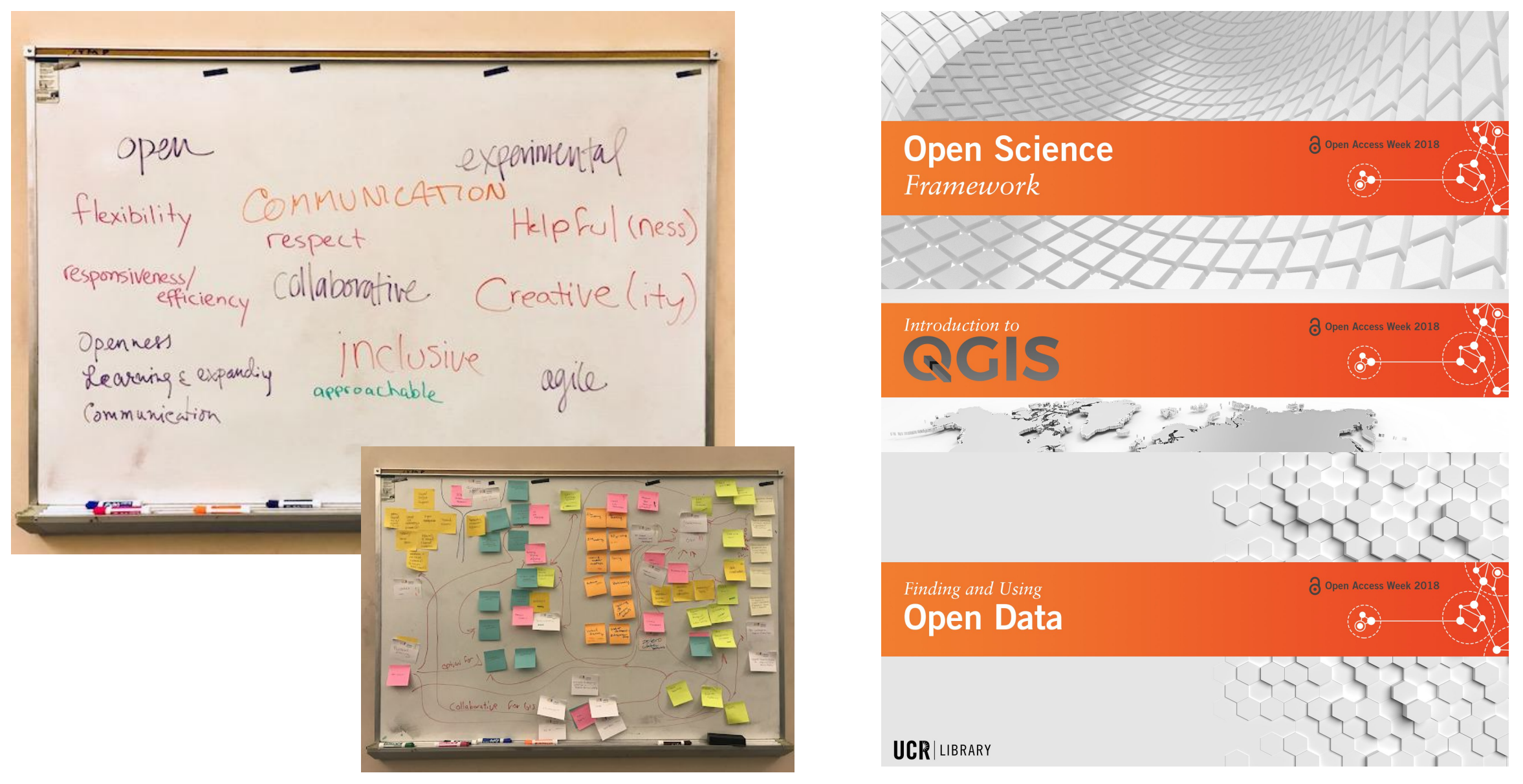


\section{Make an open project}

- Exposure to an open tool

- Teaches project management \& collaboration, including "negotiating" openness

- Builds confidence that we have something to contribute in the field 


\section{OSF guiding questions}

- Who will own the project?

- What is the project?

- What is the scope of the project? What documents do we expect to generate? What "components", if any, will our project have?

- What is out of scope?

- Who will do what?

- How will we communicate? When is email appropriate vs. when we communicate through OSF?

- What will go in the Wiki and what will go in more formal project documents such as a project charter, data management plan, a Readme, etc...

- How will we name our files?

- What file formats will we prefer?

- Will documents be stored in the OSF and will any be integrated from other systems such as Dropbox or Google Drive?

- Will our project be open or private? During the project? After the project? Is there data that needs to remain private? 


\section{Keep an eye out for unexpected opportunities}

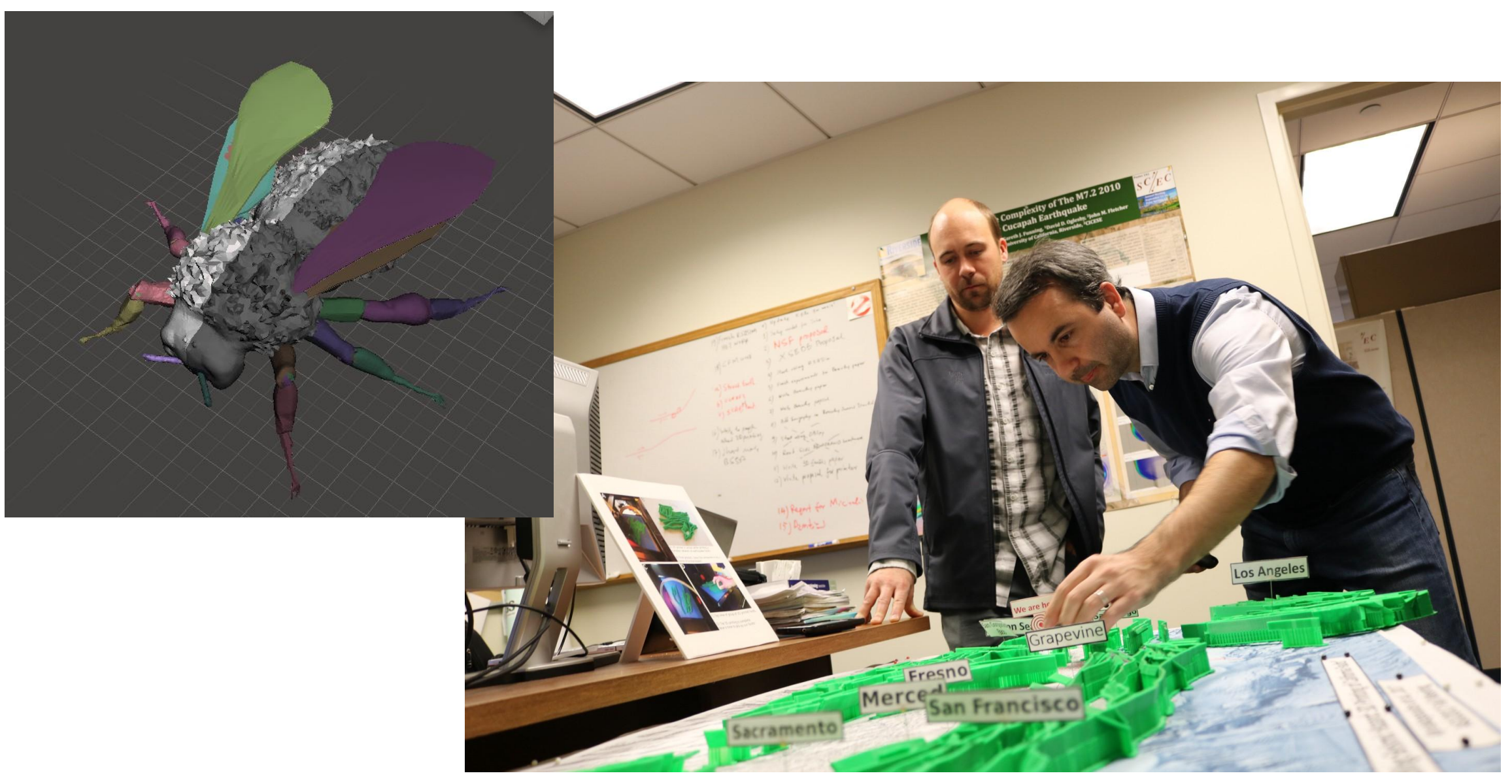




\section{Walk the talk}

Turn down journals or projects that aren't open enough.

Find, lead, or contribute to open projects.

Support open platforms to give libraries a fighting chance against a commercially monopolized scholarly workflow ecosystem...!!!

Look for ways to learn and grow your open skill set.

\section{Mozilla Open Leaders}

Mentorship and Training on Working Open

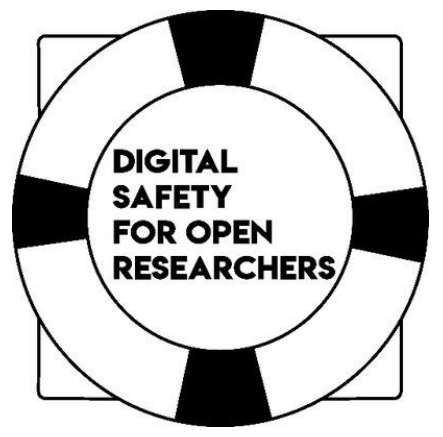

Rebus INK 


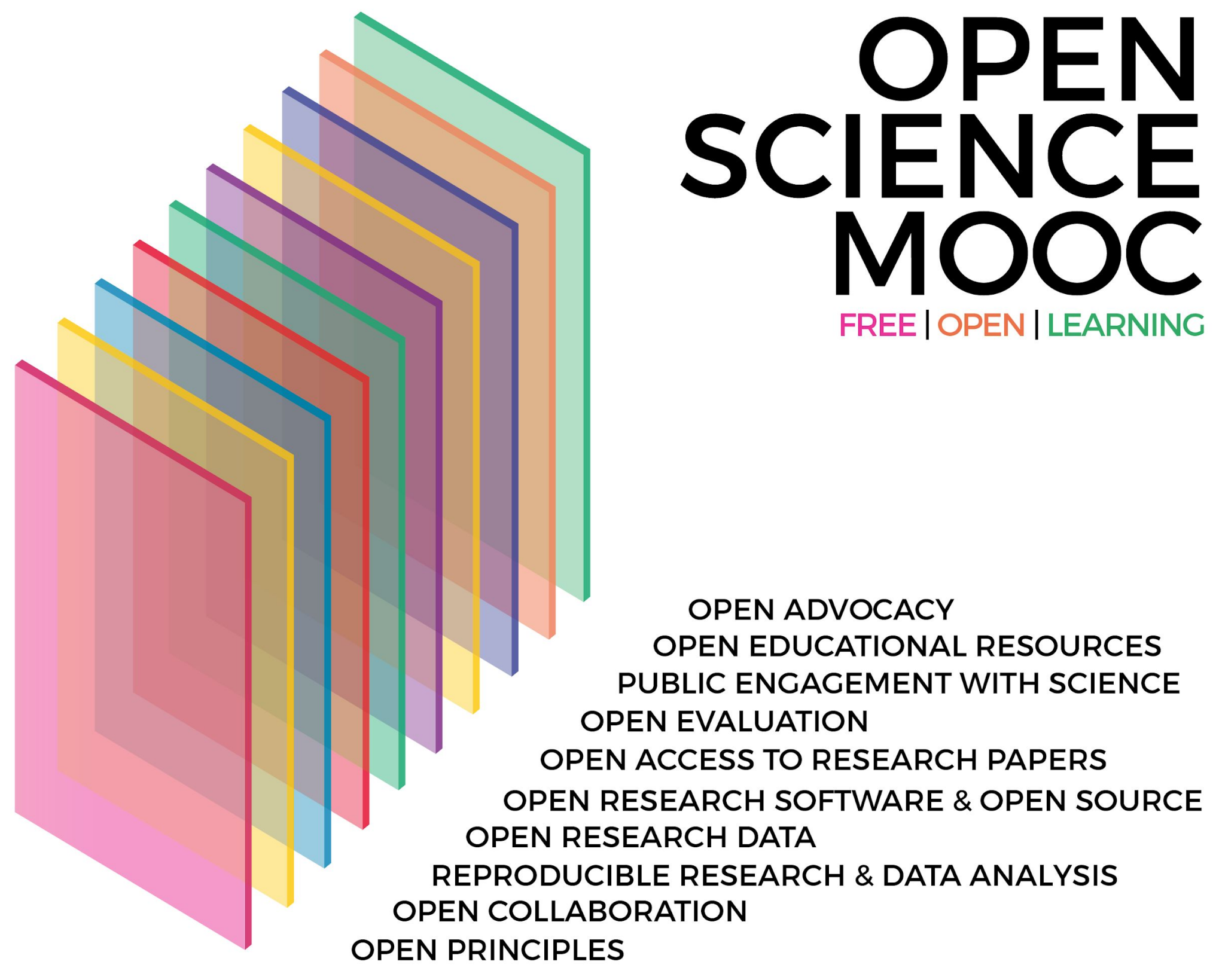

https://opensciencemooc.eu/ 


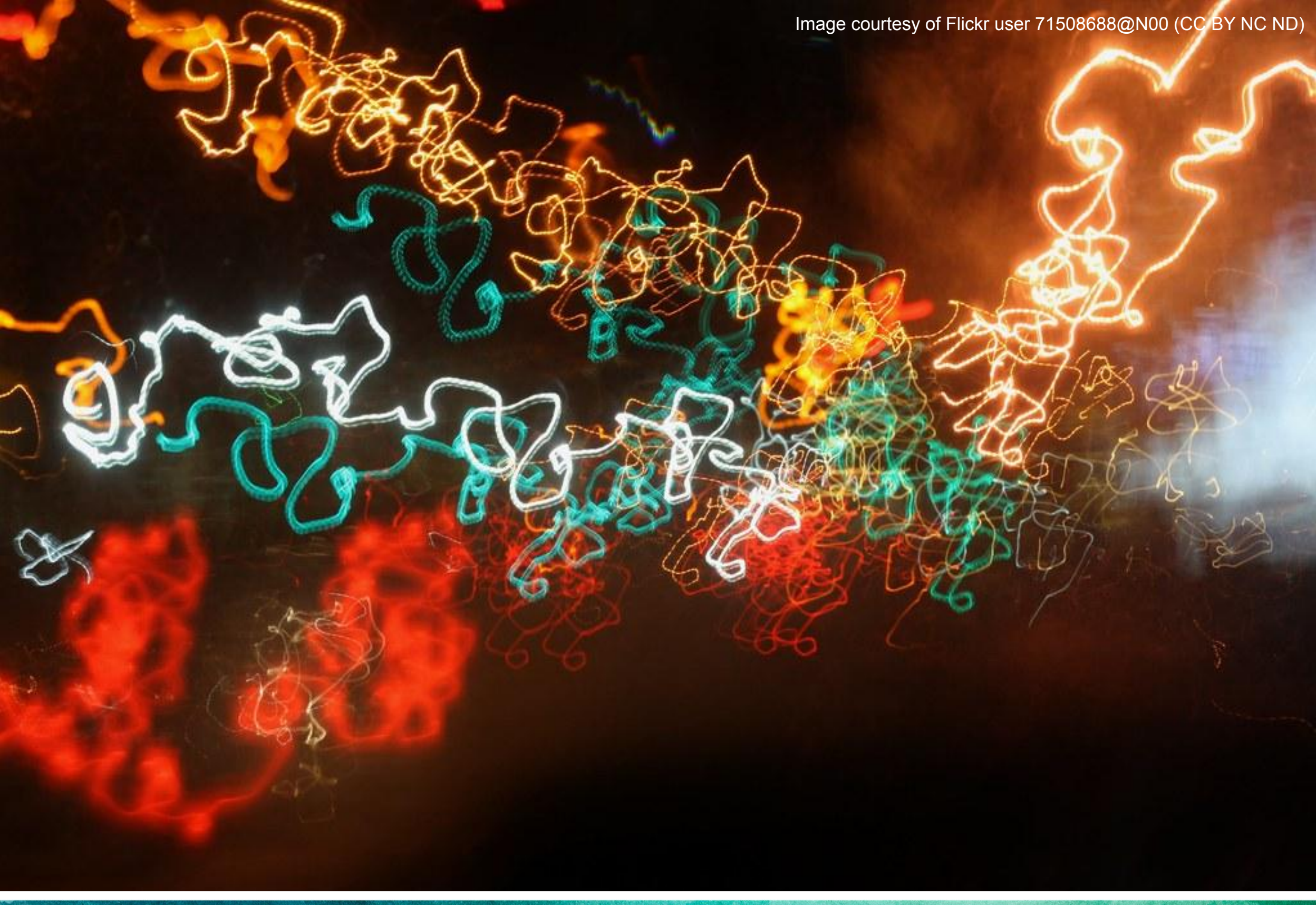

RESEARCH. 


\section{Brianna Marshall}

@notsosternlib

We talk a lot about success stories but noticeably less about failure and what we can learn from it. To anyone who practices or advocates for open access, open data, open educational resources: would you be willing to share one of your open-related failures, big or small?

1:53 PM · Apr 3, 2019 · Twitter Web App

॥l View Tweet activity

33 Retweets $\mathbf{5 2}$ Likes

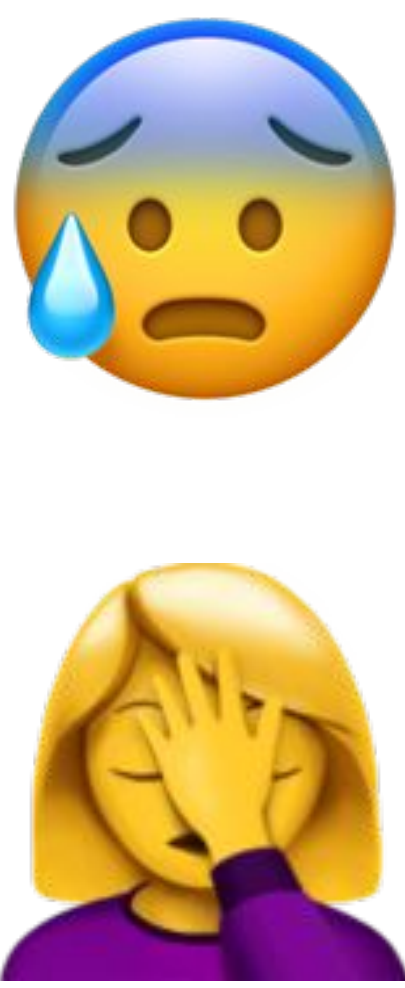


We talk a lot about success stories but noticeably less about failure and what we can learn from it. To anyone who practices or advocates for open access, open data, open educational resources: would you be willing to share one of your open-related failures, big or small?

1:53 PM · Apr 3, $2019 \cdot$ Twitter Web App

Ill View Tweet activity

$3 \mathbf{3}$ Retweets $\mathbf{5 2}$ Likes

a study's open preregistration being discovered by a possible participant

sharing preliminary work and having it used without citation

nobody except colleagues in the library coming to open-focused workshops

an organization only building an open data portal for the optics
- Looking critically at who is taking the risks and who has the privilege to fail (Gregory Palermo, @gregory_palermo; Scott B. Weingart, @scottbot; Thomas Padilla, @thomasgpadilla - link to thread)

- Importance of being able to pivot and change directions after a project isn't as successful as you'd hoped (Amanda Larson, @maeverawr - link to thread)

- Lessons from making and flying open source drones, including problems, approaches, and takeaways (Paz Bernaldo, @PazByC - link to thread) 


\section{Open lessons for managers}

- If you don't prioritize this work, who will? Make a plan.

- Open shouldn't just live within one role; it flows through work across an organization. Exploring open as a shared value helps.

- Moving to open often means going up to bat against legacy processes, fixed mindsets, and our own blind spots.

- Initiate discussions on commercially-owned infrastructure and the scholarly landscape.

- Make space for learning, mistakes, failures, and differing opinions about openness.

- Signal your open values up and out, and have strategies to gain administrative buy-in ready to go.

- Competing departmental needs affect bandwidth for open. Dedicated time matters!

- Take the long view but focus on tangible results in the short term. 


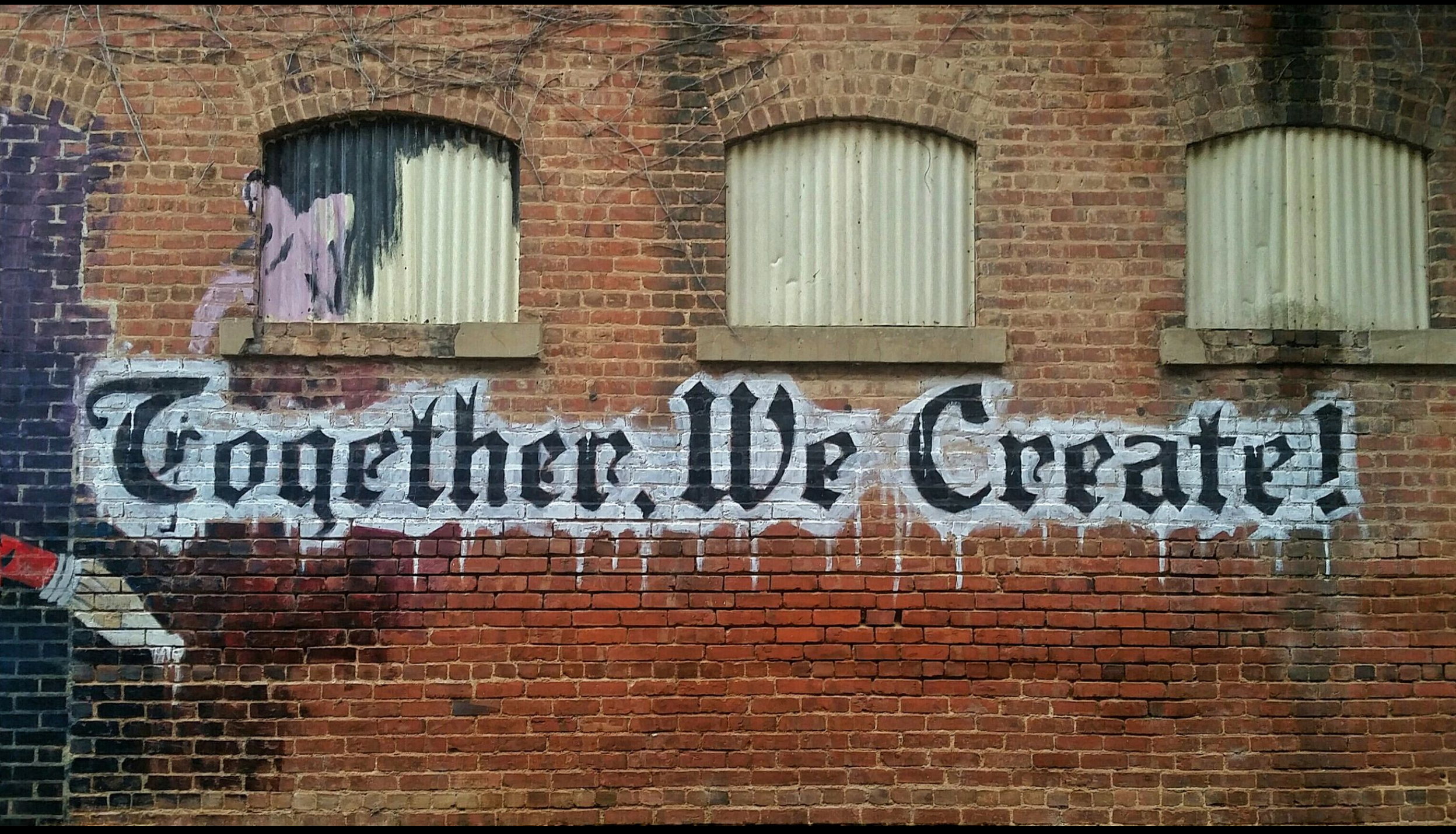

Photo by "My Life Through A Lens" on Unsplash 


\section{Building community to support open work}

Exploring how to incorporate openness in different scenarios: one-on-one coaching, targeted initiatives, team projects, open-focused roles.

Engaging colleagues outside our silos, knitting together efforts across research, teaching and learning, collection strategies, and beyond.

Talking about not just what we're doing, but HOW we're doing it... exploring how change management, project management, collaboration, and issues of diversity, equity, and inclusion impact working open at our institutions and within the profession. 


\section{Resources}

Aspesi, C., Allen, N., Crow, R., Daughtery, S., Joseph, H., McArthur, J., Shockey, N. (2019) SPARC Landscape Analysis: The Changing Academic Publishing Industry Implications for Academic Institutions. Available at: https://sparcopen.org/our-work/landscape-analysis/

Sayre, F., \& Riegelman, A. (2019). Replicable Services for Reproducible Research: A Model for Academic Libraries. College \& Research Libraries, 80(2), 260. doi: https://doi.org/10.5860/crl.80.2.260

Steeves, Vicky (2017) "Reproducibility Librarianship," Collaborative Librarianship: Vol. 9 : Iss. 2 , Article 4. Available at:

https://digitalcommons.du.edu/collaborativelibrarianship/vol9 /iss $2 / 4$

Wright, Steph (2019) "Easy is not-so-easy." Available at: https://medium.com/@stephanie 6761/easy-is-not-so-easy$\underline{82394509 c f 3 d}$

\section{Easy is not-so-easy \\ (2) Stephanie Wright Follow Mar $27.3 \mathrm{~min}$ read}

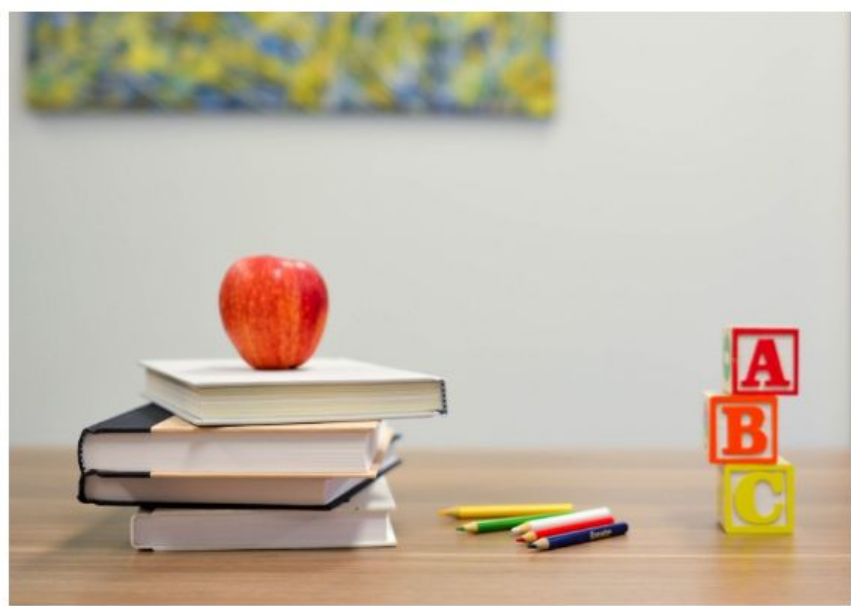

Photo by Element 5 Digital on Unsplash

It should be easy, right? A checklist of things that are "easy to do" should be easy to write. Turns out... not so much.

Even though our team cohesively agrees on the power \& value of working openly, there are so many nuances and complexities, we discovered we don't necessarily all agree on the power and value of each open practice individually. 
The Data to Policy Project (D2P) is an initiative that uses open data to explore issues related to social equity like police violence and affordable housing... research posters are presented at a symposium where we invite local lawmakers, governments, nonprofit organizations, and community members to talk with students about their proposals... A member of a local police department attended and was so impressed that [...] he wanted his department to share their data for the first time. Police transparency is good for the community and the police, and open data is one step towards achieving that... inviting the community into open research can inspire changes in practices and that we need to be more intentional about communicating the value and potential applications of open scholarship to community partners.

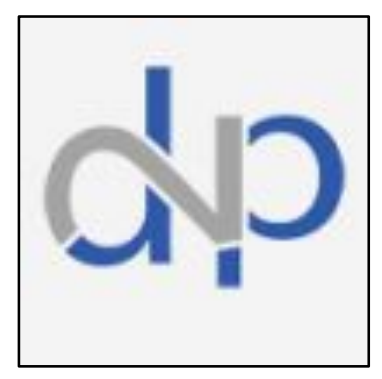

Shea Swauger is the Researcher Support Services, Department Head at the Auraria Library in Denver, Colorado. He's the Director of the Data to Policy Project and an advocate for equitable open research. https://library.auraria.edu/d2pproject

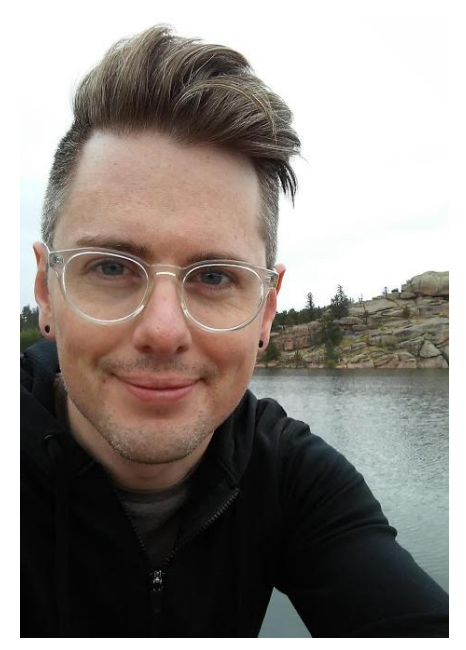




\section{Gradually, then Suddenly: Toward a More Open Future}

Successes

* Adaptability

${ }^{*}$ Coalition building - COAPI, LPC, SPARC, DLF

Failures

* Focus on the post-print journal article in the IR * Centered open on the library (serials crisis, OA policies), rather than on the researcher (evolving practices) * Reactive rather than proactive

Group notes: http://tinyurl.com/y5lxmu3x 


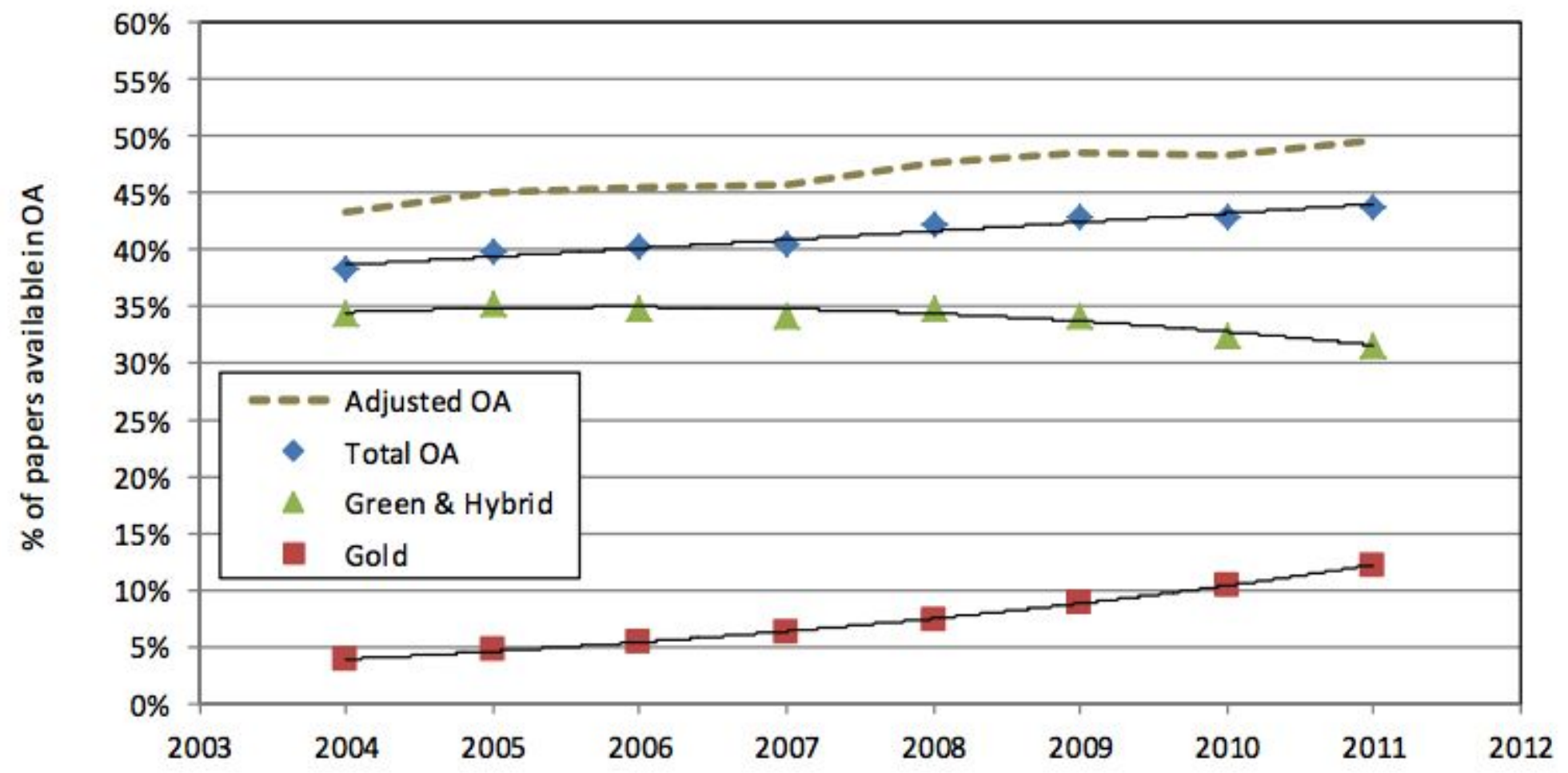

Figure 4 Per cent of freely available peer-reviewed papers, 2004-2011

Source: $\quad$ Computed by Science-Metrix using DOAJ, PubMedCentral, and Scopus. 


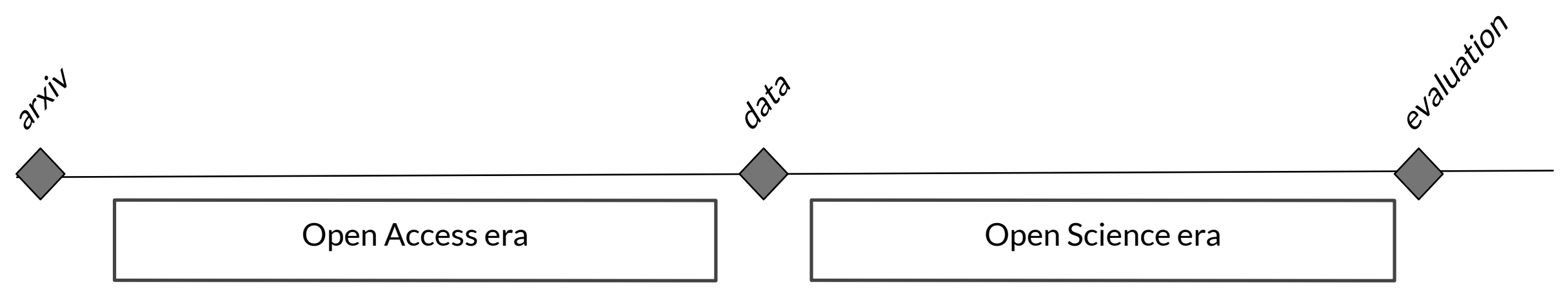



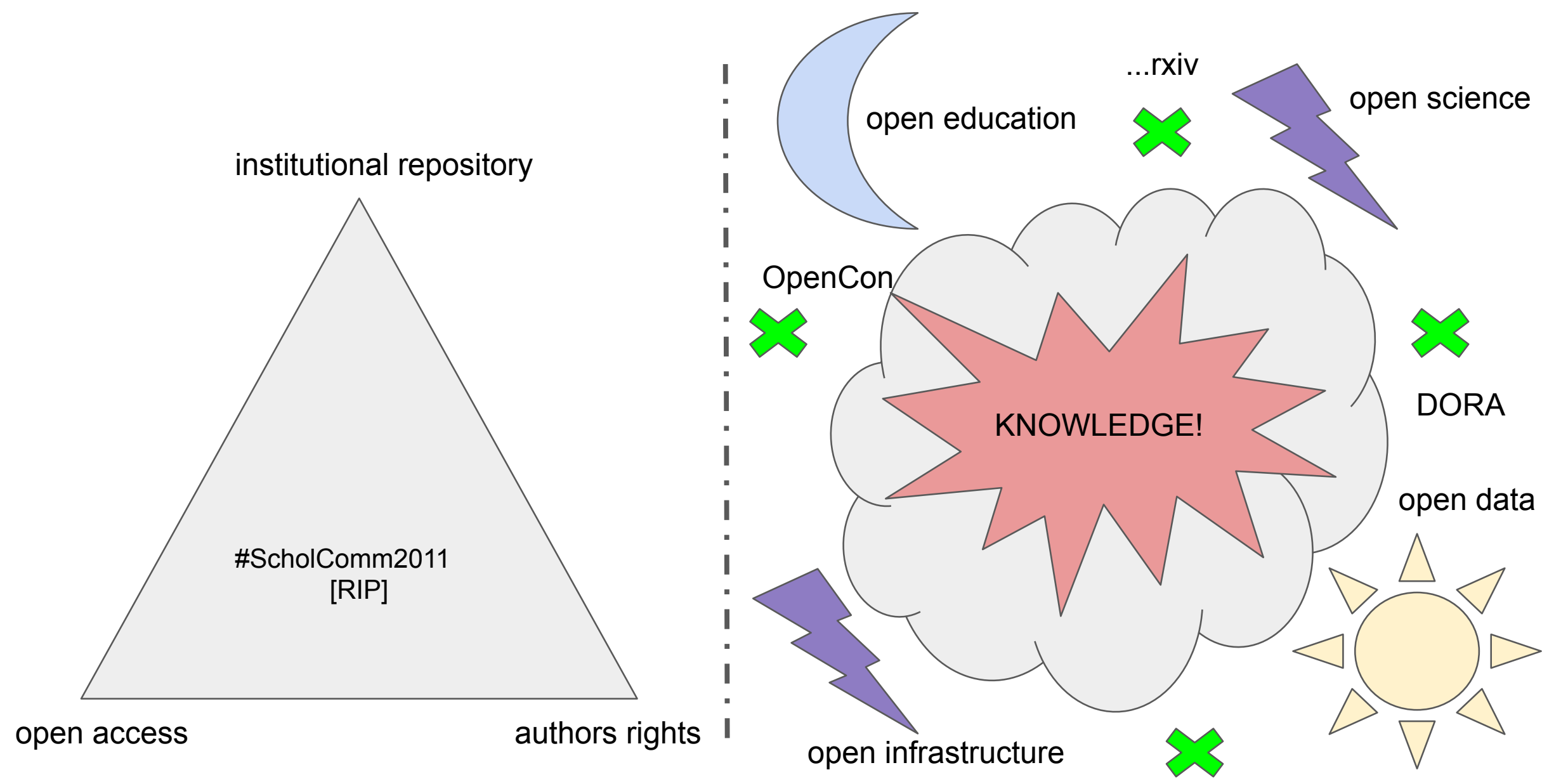

beprexit

\section{From Scholarly Communication to Open Knowledge}




\section{"An old tradition and a new technology have converged to make possible an unprecedented public good."}

budapestopenaccessinitiative.org/read

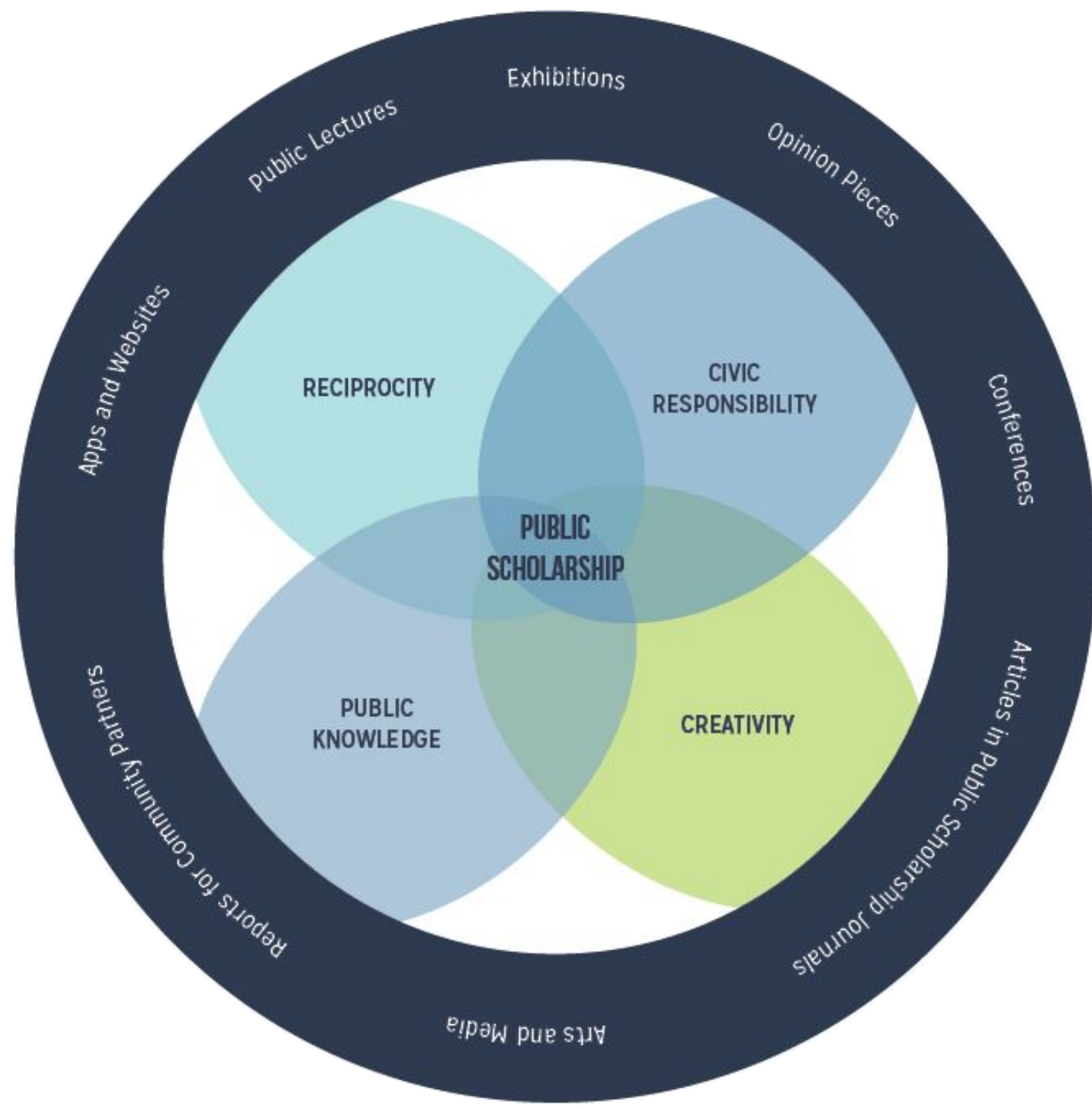

apps.carleton.edu/ccce/scholarship/what_is/

\section{From Open to Public}




\section{Chris Bourg}

\section{@mchris4duke}

someday, when i have the ti write something (a book-like something, but open and interactive) about open science and $\mathrm{i}$ will title it "It was never about the journal article." 


\section{SPARC Landscape Analysis}

\section{CREOS}

\section{Center for Research on Equitable and Open Scholarship}

\section{Mission}

Advance knowledge in service of equitable and open scholarship.

\section{Our Work}

CREOS seeks evidence about the best ways disparate communities can participate in scholarship with minimal bias or barriers.

- First, it aims to make research in every field more equitably and openly available to all who could benefit from and/or contribute to it.

- Second, it aims to accomplish the first goal by conducting and supporting original research and sharing it openly.

We believe in

- Rigorous, evidence-based research to inform actions

- Tackling grand challenges

- Multidisciplinary problem solving and methodologies

- Leading where appropriate, listening always

- The power of equitable and open scholarship to accelerate the pace of discovery and create a more robust and comprehensive knowledge base for human understanding, insight, and quality of life.

\section{libraries.mit.edu/creos/}

\section{From Analysis to Action}




\section{How significant are the public dimensions of faculty} work in review, promotion, and tenure documents?

Author(s): Juan Pablo Alperin (see profile), Carol Muñoz Nieves, Lesley Schimanski, Gustavo E. Fischman, Meredith T. Niles, Erin C. McKiernan Date: 2018

Subject(s): Altmetrics, Assessment, Higher education, Higher education policy, Open access

Item Type: Article

Tag(s): careers, metrics, tenure

Permanent URL: http://dx.doi.org/10.17613/M6W950N35

Abstract: Much of the work of universities, even private institutions, has significant public dimensions. Faculty work in particular is often funded by public funds, is aimed at serving the public good, and is subject to public evaluation. To understand how the public dimensions of faculty work are valued, we analyzed review, tenure and promotion documents from a representative sample of 129 Canadian and American universities. We found terms and concepts related to public and community are mentioned in a large portion of documents, but mostly in ways that relate to service-an undervalued aspect of academic careers. Moreover, we find significant mentions of traditional research outputs and citation-based metrics. Such outputs and metrics reward faculty work targeted to academics, and mostly disregard the public dimensions. We conclude that institutions that want to live up to their public mission need to work towards systemic change in how faculty work is assessed and incentivized.

Alperin, J.P., Muñoz Nieves, C., Schimanski, L., Fischman, G.E., Niles, M.T. \& McKiernan, E.C. (2018). How significant are the public dimensions of faculty work in review, promotion, and tenure documents? Humanities Commons [preprint]. doi: http://dx.doi.org/10.17613/M6W950N35

\section{Use of the Journal Impact Factor in academic review, promotion, and tenure evaluations}

Research article Science Policy

Erin C. McKiernan ${ }^{1}$ 1, Lesley A. Schimanski², Carol Muñoz Nieves ${ }^{2}$, Lisa Matthias ${ }^{3}$, Meredith T. Niles ${ }^{4}$, Juan Pablo Alperin 2,5

April 9, 2019

$\checkmark$ Author and article information

${ }^{1}$ Departamento de Física, Facultad de Ciencias, Universidad Nacional Autónoma de México, Cuidad de México, CDMX, Mexico

2 Scholarly Communications Lab, Simon Fraser University, Vancouver, British Columbia, Canada

3 John F. Kennedy Institute, Freie Universität Berlin, Berlin, Brandenburg, Germany

${ }^{4}$ Department of Nutrition and Food Sciences, Food Systems Program, University of Vermont, Burlington, Vermont, United States

${ }^{5}$ School of Publishing, Simon Fraser University, Vancouver, British Columbia, Canada

DOI

10.7287/peerj.preprints.27638v2

McKiernan EC, Schimanski LA, Muñoz Nieves C, Matthias L, Niles MT, Alperin JP. 2019. Use of the Journal Impact Factor in academic review, promotion, and tenure evaluations. PeerJ

Preprints 7:e27638v2

https://doi.org/10.7287/peerj.preprints.27638v2 


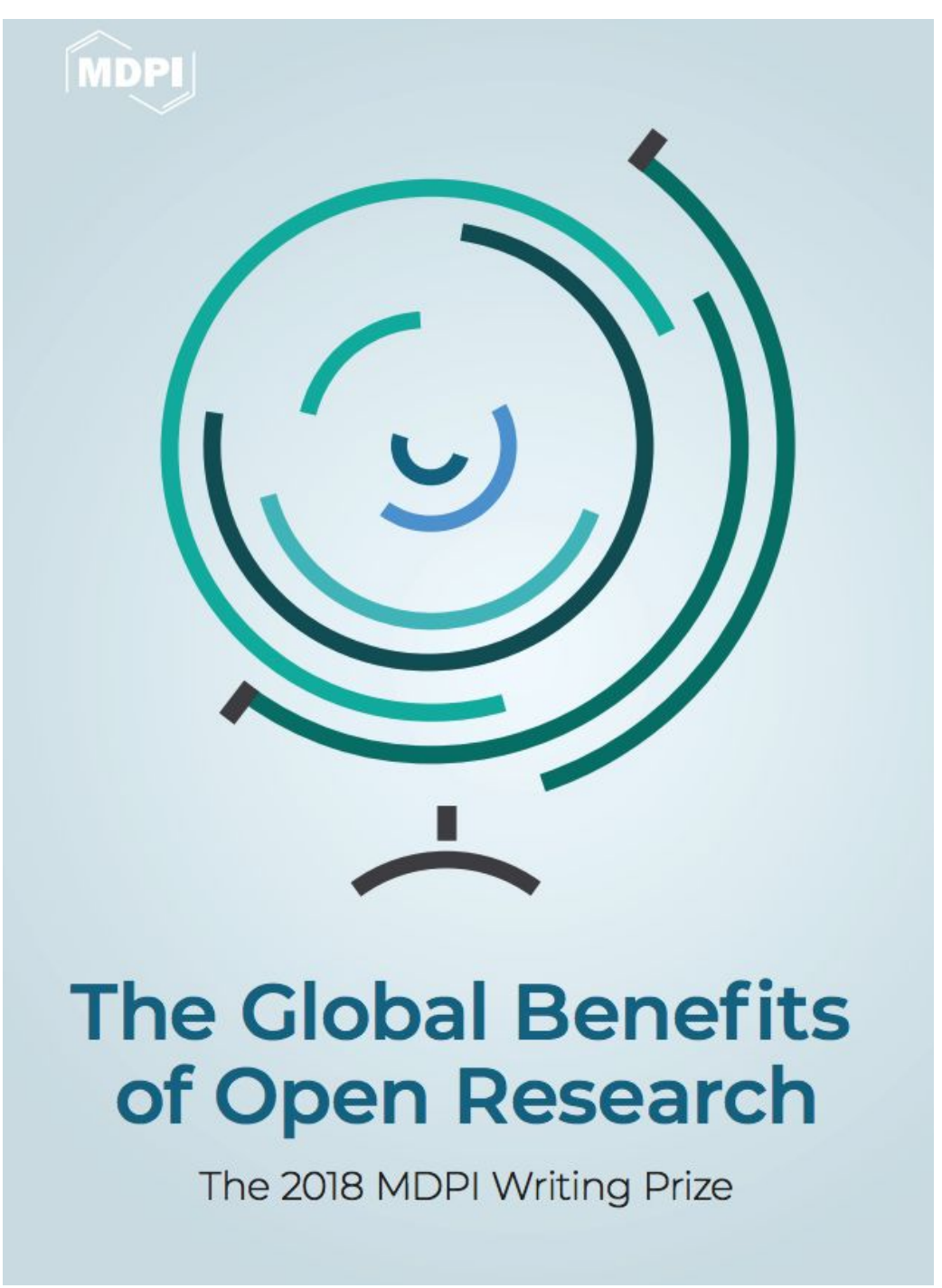

The Global Benefits of Open Research. mdpi.com/books/pdfview/edition/914
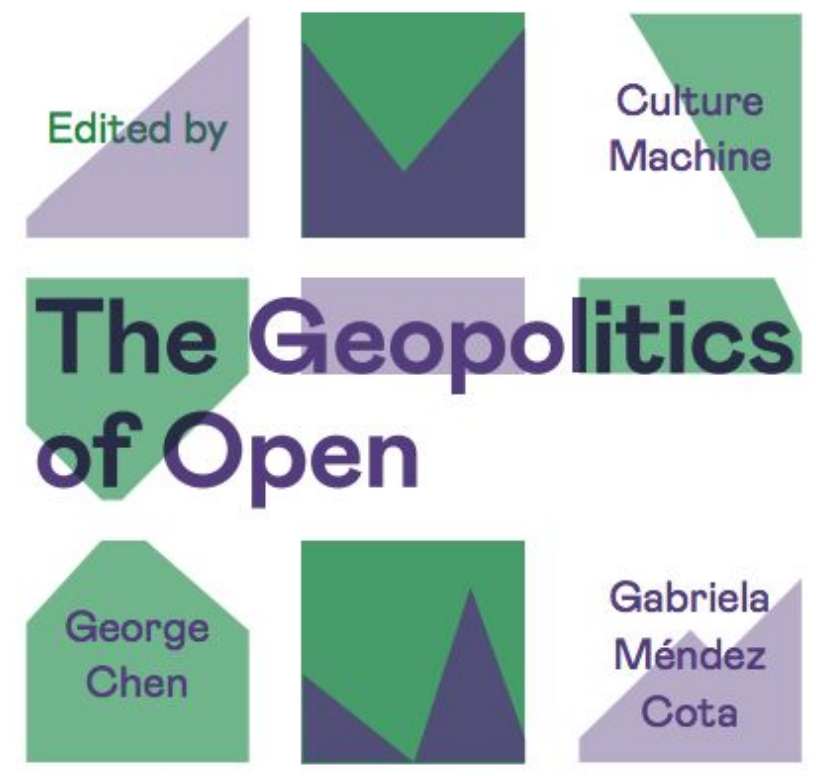

Gabriela Méndez Cota
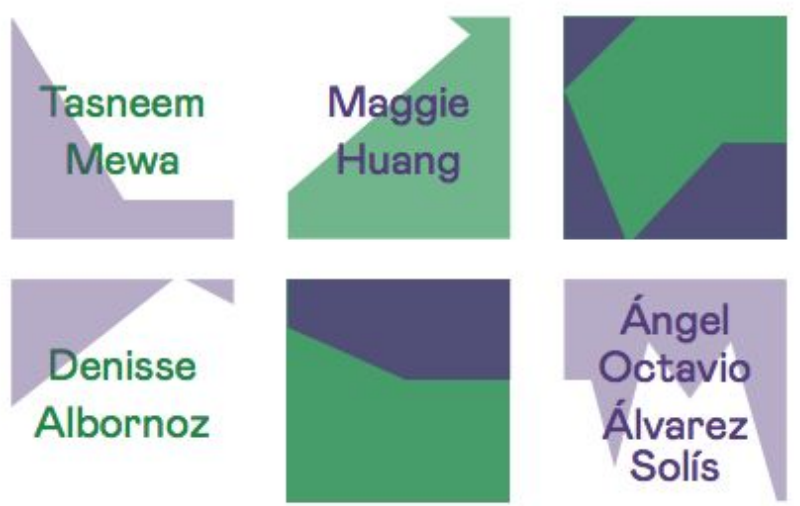

Albornoz, D., Chen, G. (Zhiwen), Huang, M., Mewa, T., Cota, G. M., \& Solís, Á. O. Á. (2018). The Geopolitics of Open. hcommons.org/deposits/item/hc:19819/

\section{Think Global, Act Local}




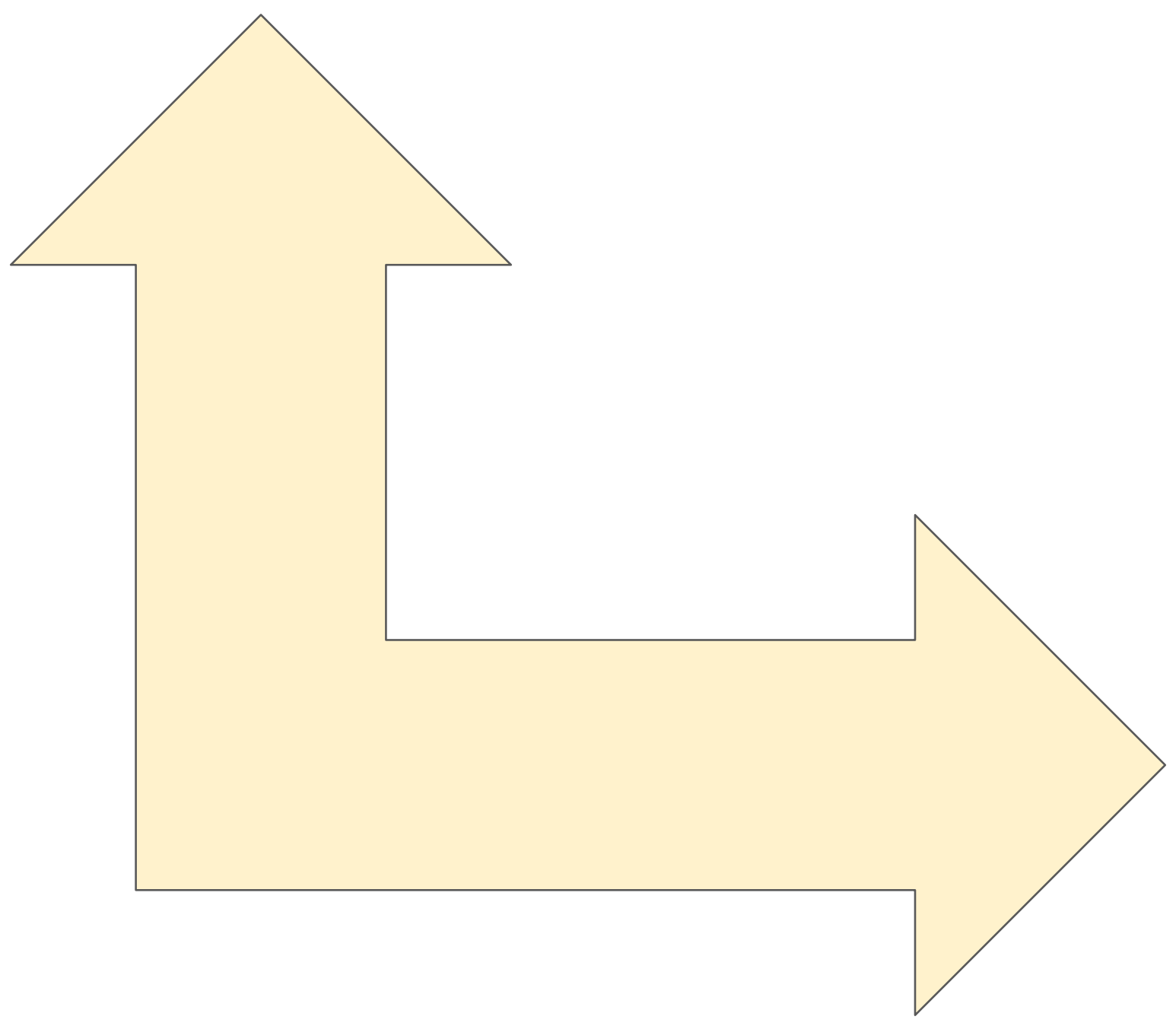

Outward and Upward 


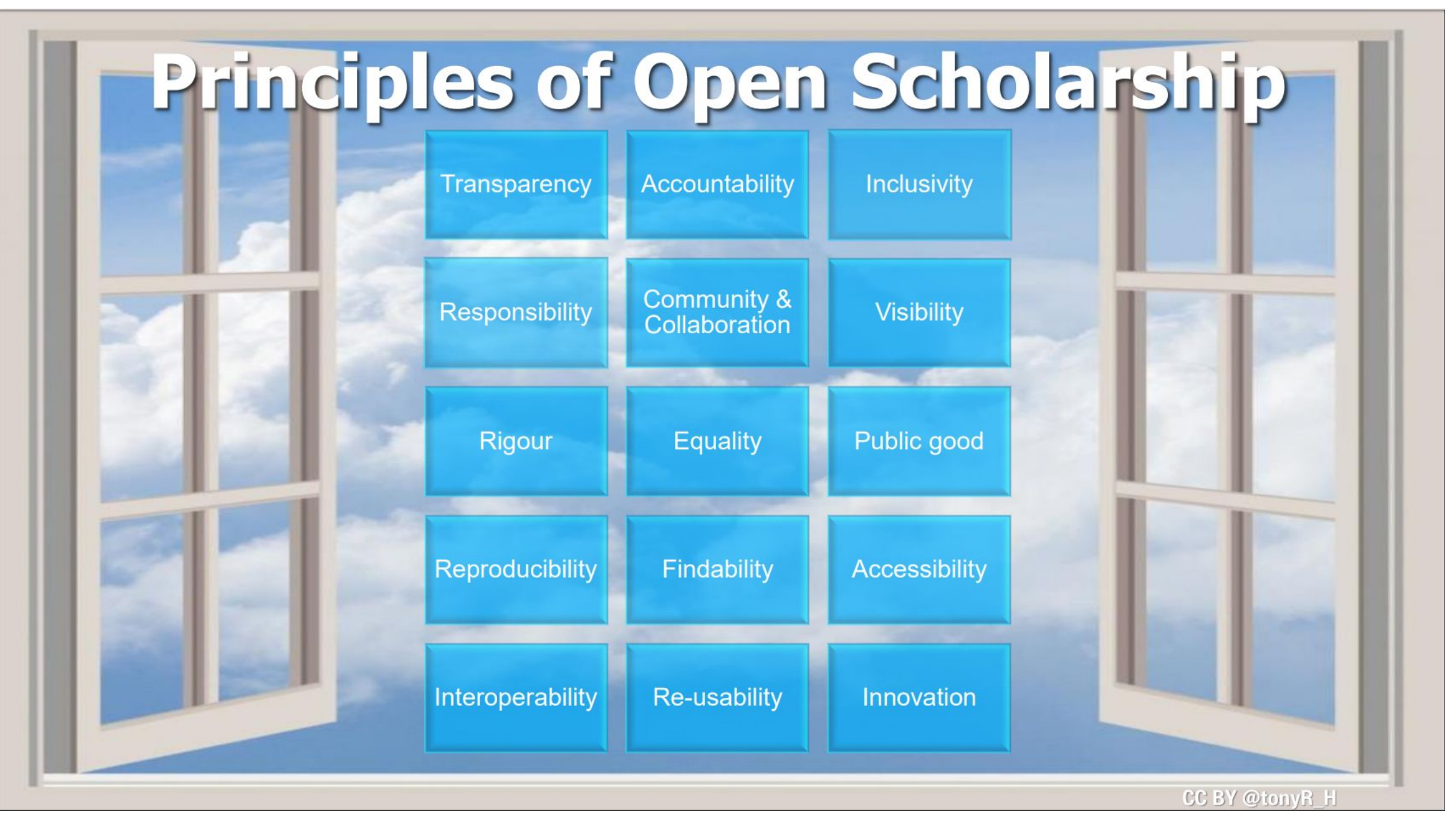

From: https://open-scholarship-strategy.github.io/site/ which got it from https://www.slideshare.net/OpenAIRE eu/peer-review-in-the-age-of-open-science

\section{From Principles to Practice}




\section{From Principles to Practice}

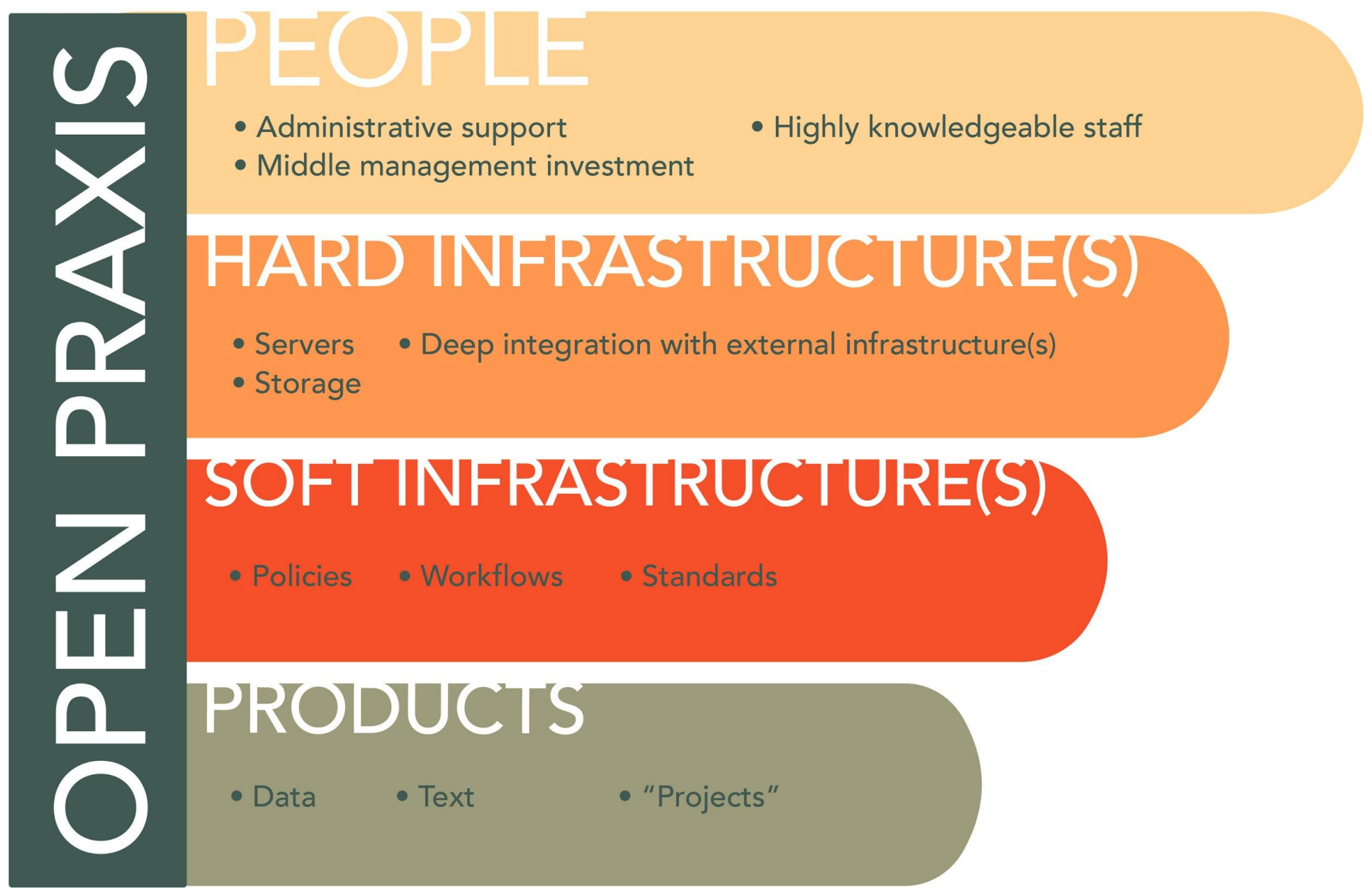

Vandegrift, Micah, \& Vandegrift, Abby. (2019). A Model for Institutional Support for Open Praxis http://doi.org/10.5281/zenodo.2633343

Adapted from Wolski, M., \& Richardson, J.'s "A Model for Institutional Infrastructure to Support Digital Scholarship." https://doi.org/10.3390/publications2040083 
* Adaptability

* Coalition building - COAPI, LPC, SPARC, DLF

\section{Failures}

* Focus on the post-print journal article in the IR

* Centered open on the library (serials crisis), rather than on

the researcher (evolving practices)

* Reactive rather than proactive

Evolutions

* Focus on changing behaviors AND culture

* Center on the researcher

* Be proactive - invest in open at the discipline, and consortial/regional level 
Openness is aligned with core values of LIS, including equal access to information, community-based infrastructure and knowledge, education/scholarship as a public good, and preservation and dissemination of the scholarly record.

LIS professionals have a great opportunity to lead and build communities around these ideals both within their institutions as well as in the LIS field itself. 


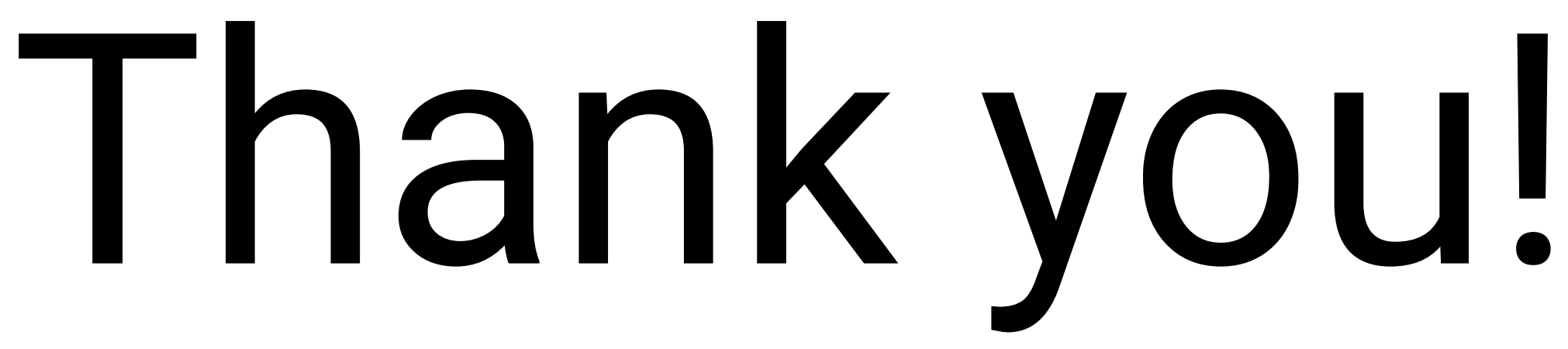

Brianna Marshall | brianna.marshall@ucr.edu

Vicky Steeves I vicky.steeves@nyu.edu

Micah Vandegrift | mlvandeg@ncsu.edu

Group notes: http://tinyurl.com/y5lxmu3x 